\title{
Swimming kinematics and efficiency of entangled North Atlantic right whales
}

\author{
Julie M. van der Hoop ${ }^{1,2, *}$, Douglas P. Nowacek ${ }^{3}$, Michael J. Moore ${ }^{2}$, \\ M. S. Triantafyllou ${ }^{4}$ \\ ${ }^{1}$ Massachusetts Institute of Technology-Woods Hole Oceanographic Institution Joint Program in Oceanography/ \\ Applied Ocean Science and Engineering, Cambridge, MA 02139, USA \\ ${ }^{2}$ Biology Department, Woods Hole Oceanographic Institution, Woods Hole, MA 02543, USA \\ ${ }^{3}$ Nicholas School of the Environment and Pratt School of Engineering, Duke University Marine Lab, \\ 135 Duke Marine Lab Rd, Beaufort, NC 28516, USA \\ ${ }^{4}$ Mechanical Engineering, Massachusetts Institute of Technology, Cambridge, MA 02139, USA
}

\begin{abstract}
Marine mammals are streamlined for efficient movement in their relatively viscous fluid environment and are able to alter their kinematics (i.e. fluke stroke frequency, amplitude, or both) in response to changes in force balance. Entanglement in fishing gear adds significant drag and buoyant forces that can impact swimming behaviors across a range of timescales. We deployed biologging tags during the disentanglement of 2 North Atlantic right whales Eubalaena glacialis to (1) examine how their kinematics changed in response to drag and buoyancy from entanglement in fishing gear, and (2) calculate resultant changes in swimming efficiency for one individual. We observed variable responses in dive behavior, but neither whale appeared to exploit added buoyancy to reduce energy expenditure. While some of the observed changes in behavior were individually specific, some swimming kinematics were consistently modulated in response to high drag and buoyancy associated with entangling gear, affecting thrust production. In high drag and buoyancy conditions, fluke strokes were significantly shorter and more variable in shape, and gliding was less frequent. Thrust and efficiency significantly differed among dive phases. Disentanglement reduced thrust coefficients $\sim 4$-fold, leading to 1.2 to 1.8 -fold lower power (W). Ideal propulsive efficiency was significantly lower when entangled, though we detected no difference in observed propulsive efficiency between the conditions. Similar to carrying heavy objects or changing shoes, we present another condition where animals perceive unique movement constraints over seconds to minutes and develop compensatory strategies, altering their movement accordingly.
\end{abstract}

KEY WORDS: Gait change $\cdot$ Compensation $\cdot$ DTAG $\cdot$ Buoyancy $\cdot$ Drag

\section{INTRODUCTION}

Marine mammals are streamlined to optimize efficient movement in their relatively viscous fluid environment. Changes in the vertical and horizontal force balances on marine animals have been shown to affect energy consumption (Ponganis et al. 1990, Kooyman \& Ponganis 1994) while also influencing swimming behavior and kinematics - the form, pat-

${ }^{*}$ Corresponding author: jvanderhoop@whoi.edu tern, or sequence of movement with respect to time. To overcome additional drag forces, individuals increase thrust by altering fluke stroke frequency, amplitude, or a combination of both (Skrovan et al. 1999, Williams 1999, Cornick et al. 2006, Aoki et al. 2011); alternatively, individuals can minimize the increase in drag by swimming at slower speeds (Lang \& Daybell 1963, Boyd et al. 1997, Cornick et al. 2006, van der Hoop et al. 2014a). Marine mammals

(C) The authors 2017. Open Access under Creative Commons by Attribution Licence. Use, distribution and reproduction are unrestricted. Authors and original publication must be credited. 
tend to respond to natural (e.g. lipid loss or gain, lung compression; Biuw et al. 2003, Nousek-McGregor et al. 2014) or experimental (Skrovan et al. 1999, Aoki et al. 2011) changes in buoyancy by reducing thrust output or by gliding in the buoyancy-aided direction to maximize swimming efficiency when possible. Swimming animals therefore show plasticity in their ability to adjust their fine-scale movement patterns in response to changes in drag and buoyant forces and moments to optimize propulsive efficiency within constraints (Fish 1999).

Entanglement in fishing gear is the leading cause of death to large whales in the western North Atlantic (van der Hoop et al. 2013), and within this region, sublethal entanglement affects $83 \%$ of the North Atlantic right whale Eubalaena glacialis (hereafter right whale) population (Knowlton et al. 2012). Most recorded right whale entanglement cases involve whales that swim while towing gear that is no longer anchored (NMFS 2003). These whales are subject to 1.5-fold increases in drag on average, with some gear configurations increasing drag up to 3.1-fold (van der Hoop et al. 2016). An additional consideration is buoyancy. Right whale buoyancy likely ranges $\pm 1000 \mathrm{~N}$ depending on nutritional condition and life stage; most right whales are positively buoyant (Miller et al. 2004, Nowacek et al. 2001, Nousek-McGregor et al. 2014). Some entangling sets of fishing gear include floats and buoys that can add 26 to $665 \mathrm{~N}$ of buoyancy. Disentanglement response teams are trained to add buoys to increase drag and buoyancy to slow entangled whales and facilitate their disentanglement, a process referred to as 'kegging' (NMFS 2003). Further, many disentanglement operations require the addition of a satellite telemetry buoy to track entangled whales until conditions (e.g. equipment, personnel, weather or time of day) favor further attempts at gear removal; this contributes more drag and buoyancy. Entanglement in, and disentanglement from, fishing gear therefore presents a unique context in which to examine individual responses to changes in force balance.

If swimming animals optimize their performance, especially during sub-optimal conditions such as entanglement, changes in their swimming kinematics (i.e. their fluke stroke frequency or amplitude) or gaits in response to drag and buoyancy loading should be detectable. The effects of entanglementrelated drag and buoyancy on the swimming behavior of 1 right whale were quantified by deploying a biologging tag (DTAG; Johnson \& Tyack 2003) during a disentanglement operation in 2011 (van der
Hoop et al. 2014b). We deployed a second tag prior to a disentanglement attempt on a second whale; a portion of entangling gear was removed and a satellite telemetry buoy added to track the whale for another disentanglement attempt the following day. Here, we examine tag data from these 2 entangled whales with differences in natural and added drag and buoyant forces, manipulated during disentanglement procedures, with the expectations that: (1) fluke strokes and swimming speed would be altered to maintain normal power output under high drag loading conditions (Skrovan et al. 1999, Simon et al. 2012, van der Hoop et al. 2014a); (2) individuals should take advantage of added buoyancy, reducing thrust and increasing speed in the buoyancy-aided direction (Aoki et al. 2011, Miller et al. 2012, Nousek-McGregor et al. 2014); and (3) swimming efficiency would be reduced when entangled. Together, these hypotheses address whether animals maintain optimal swimming under drag loading, or whether physiological and anatomical constraints limit the plasticity of these parameters and the maintenance of efficient swimming techniques under high loading conditions (Methling et al. 2011, Nudds et al. 2014, Shimojo et al. 2014).

\section{MATERIALS AND METHODS}

We used DTAG data from 2 entangled right whales (North Atlantic Right Whale Consortium Catalog Numbers Eg 3911 and Eg 4057) to resolve changes in dive behavior, kinematics, swimming efficiency and power output. We tagged the 2 entangled whales prior to their partial disentanglement, described below. Due to the differences in their disentanglement procedures and equipment deployed and recovered, we hypothesized that Eg 3911 and Eg 4057 experienced periods of relative low and high drag and buoyancy loading from the gear (see Fig. 1); we therefore compared diving behavior and kinematics between these periods.

\section{Case histories}

We compiled individual entanglement histories from data from the North Atlantic Right Whale Consortium Database (NARWC 2015) and from members of the Atlantic Large Whale Disentanglement Network involved in the separate disentanglement attempts. For each whale, we estimated the drag forces $(\mathrm{N})$ on the entangling fishing gear 
from gear length $(\mathrm{m})$ using the length-drag relationship established in van der Hoop et al. (2016). We estimated these drag forces throughout the course of disentanglement procedures as portions of entangling gear were removed. The method in van der Hoop et al. (2016) estimates average drag over the range of speeds tested $\left(\sim 0.7\right.$ to $\left.2.1 \mathrm{~m} \mathrm{~s}^{-1}\right)$; we assumed constant drag at this average value, and did not alter these estimates of drag based on dive descent or ascent rates. We estimated buoyant forces from available manufacturer information (Scanmarin, Polyform). We estimated the total drag on both whales based on a turbulent spindle model as in van der Hoop et al. (2014b) with drag augmentation factors for appendages $(g=1.3)$ and body oscillation $(k=1.5 \pm 10 \%$; Fig. S1 in the Supplement at www.int-res.com/articles/suppl/n032 p001_supp.pdf).

Eg 3911 was a severely emaciated (approximately $20 \%$ thinner than normal right whales; van der Hoop et al. 2014b), 2-yr-old, $10 \mathrm{~m}$ female at the time of the third and final multi-agency disentanglement effort on 15 January 2011 near Melbourne, Florida, USA. To facilitate this disentanglement, we injected a mixture of analgesic and anti-anxiety drugs via ballistic syringe $20 \mathrm{~min}$ after we attached the DTAG; the effect of this drug mixture on right whales has been briefly described but remains only partially understood (Moore et al. 2010, van der Hoop et al. 2014b). We placed the tag just above the right lateral midline, midway between the blowhole and tail (van der Hoop et al. 2014b, their Fig. 3).

Eg 4057 was a 3-yr-old male when first sighted entangled on 16 February 2014 off Jacksonville, Florida. His most recent pre-entanglement sighting was 11 mo prior on 18 March 2013 in Cape Cod Bay, Massachusetts; his body condition was observed and evaluated as fair (i.e. not emaciated) in both sightings. Prior to the disentanglement effort, we attached a DTAG on the left flank (see Fig. 1D).

\section{Tag data analysis}

The DTAG includes a pressure sensor and 3-axis accelerometers and magnetometers sampling at $50 \mathrm{~Hz}$, though we down-sampled sensor data to $5 \mathrm{~Hz}$ for analysis. We derived pitch, roll and heading from the accelerometer and magnetometer signals after correcting for the orientation of the tags on the whales (Johnson \& Tyack 2003, Johnson 2015), and for tag movement during the deployment on $\mathrm{Eg}$ 4057.

\section{Dive parameters}

We defined dives as departures from the surface to $>5 \mathrm{~m}$. We obtained water-column depth from nautical charts (GPS Geoplaner, www.geoplaner.com) for GPS waypoints from follow vessels and aircraft during the disentanglement procedures. We visually determined descent and ascent portions of dives from the DTAG depth record. We calculated descent and ascent rates of each dive as the change in depth/time. We used these rates as estimated swimming speeds in further analyses, and note they are a lower bound of speed as they represent change in only one dimension. We calculated the expected descent and ascent rates $\left(U_{\text {exp }} \mathrm{m} \mathrm{s}^{-1}\right)$ as those at which the whales would have to swim to maintain non-entangled drag forces under the entangled condition (Fig. S1). To do so, we calculated the drag force for each dive descent and ascent with their observed descent or ascent rates in either the high-drag or lowdrag conditions. We fit polynomial functions to the relationship between speed and drag for each condition, and then determined the swimming speed $(U, \mathrm{~m}$ $\mathrm{s}^{-1}$ ) that would result in the same low-drag force in the high-drag condition, for each descent and ascent. We calculated the observed change in swimming speed as:

$$
\Delta U_{\text {obs }}=\left(\overline{U_{\text {low }}}-\overline{U_{\text {high }}}\right) / \overline{U_{\text {low }}}
$$

and the expected change in swimming speed as:

$$
\Delta U_{\exp }=\left(\overline{U_{\text {low }}}-\overline{U_{\text {exp }}}\right) / \overline{U_{\text {low }}}
$$

\section{Kinematic parameters}

We calculated pitch deviation as the difference between the mean and instantaneous body posture accelerometer and magnetometer matrices as in Simon et al. (2012). We used peak detection algorithms to detect peaks in the pitch deviation signal which represent individual fluke strokes (Johnson \& Tyack 2003, Johnson 2015). We calculated the duration of each fluke stroke (s) (i.e. the time between peaks) for the descent, ascent, and bottom phases of each dive, and at the surface between dives. We calculated fluke stroke frequency $(f, \mathrm{~Hz})$ as the number of fluke strokes divided by the duration of each phase (s). Following convention (Woodward 2006, NousekMcGregor et al. 2014, van der Hoop et al. 2014b, Johnson 2015), we transformed the pitch deviation signal with the Hilbert transform to detect glides as periods of oscillations $<0.4$ radians for $>5 \mathrm{~s}$. 
Amplitude, thrust, efficiency and power estimates

We were only able to calculate peak-to-peak fluke stroke amplitude $(A, \mathrm{~m})$, thrust, efficiency and power estimates for $\mathrm{Eg} \mathrm{3911;} \mathrm{fluke} \mathrm{stroke} \mathrm{ampli-}$ tudes could not be estimated from the tag on Eg 4057 because it moved during the deployment. The tag sensors measure movements at the point of tag attachment and not at the position of the flukes. We therefore estimated $A$ by calculating maxima and minima of the pitch deviation oscillations as measured on the tag, and then scaled the average amplitude to body length $(L, \mathrm{~m})$. We assumed that for normal swimming, $A$ is a constant proportion of $L$ (i.e. insensitive to speed), $\sim 0.2 \times L$ (Webb 1975b, Fish et al. 2003). When accelerating, $A$ in dolphins can be as high as $0.5 \times L$ (Skrovan et al. 1999). We scaled the mean measured $A$ in the low-drag condition, representing 'normal' swimming behavior, to $L$ (10 $\mathrm{m}$ for $\mathrm{Eg} 3911$, so mean $=2 \mathrm{~m}$ ) and then applied this scaling factor to the recorded pitch amplitudes in the high-drag condition.

We calculated the total drag $(D, \mathrm{~N})$ on $\mathrm{Eg} 3911$ based on a turbulent spindle model as in van der Hoop et al. (2014b) with drag augmentation factors for appendages $(g=1.3)$ and body oscillation $(k=1.5$ $\pm 10 \%$ ). We calculated the surface wave drag augmentation factor $(\gamma)$ from Eg 3911's median submergence depth when entangled (3.68 $\mathrm{m}, \gamma=1.75)$ and after disentanglement $(10.68 \mathrm{~m}, \gamma=1)$. We calculated $D$ on the whale when it was entangled and after disentanglement, when some gear remained, by adding the estimated average $D$ on the gear (with floats) established in van der Hoop et al. (2016; see 'Case histories'). We used this relationship instead of the values measured in van der Hoop et al. (2014b) because only a portion of the gear present during the tag deployment was measured in that study.

We were interested in determining if the kinematic changes observed in Eg 3911 affected thrust production and overall swimming efficiency. Thrust forces are better reported as a non-dimensionalized thrust coefficient, $C_{\mathrm{T}}$, which allows for better comparison across e.g. speed or size. For reference, $C_{\mathrm{T}}$ ranges from 0.3 to 1.6 in odontocetes (Fish \& Lauder 2006). Efficiency can be estimated from $C_{\mathrm{T}}$ : we calculated the average thrust coefficient for each dive descent and ascent from tag data when the whale was entangled (high drag) and after disentanglement (low drag), and for the whale when non-entangled as:

$$
C_{\mathrm{T}}=\frac{2 D}{\rho U^{2} A S}
$$

where $\rho$ is seawater density $\left(1025 \mathrm{~kg} \mathrm{~m}^{-3}\right)$, and $S$ is the span of the tail fluke $(\mathrm{m})$ calculated from the morphometric relationship based on $L$ in Moore et al. (2004). For reference, we also estimated $C_{\mathrm{T}}$ for the non-entangled condition across the full range of speeds using the drag of the non-entangled whale and the mean $\pm \mathrm{SD} A$ of the whale when disentangled as these provide the best-informed approximation.

We calculated the ideal efficiency $\left(\eta_{\mathrm{i}}\right)$ from $C_{\mathrm{T}}$ based on actuator disc theory (Prandtl 1952, Anderson et al. 1998) as:

$$
\eta_{\mathrm{i}}=\frac{2}{1+\sqrt{1+C_{\mathrm{T}}}}
$$

$\eta_{i}$ represents the upper limit of achievable propulsive efficiency $\left(\eta_{p}\right)$ and is always greater than $\eta_{p}$, the actual efficiency achieved by the whale. $\eta_{i}$ does not account for viscous, rotational losses and inefficiencies from non-uniform loading (Rayner 1979, Blake 1983, Muijres et al. 2011). $\eta_{\mathrm{i}}$ therefore illustrates the general trends and the degree to which the optimal performance of the system is affected by different entanglement conditions.

$\eta_{p}$ can be estimated from a combination of swimming movements, animal morphology and an understanding of wake structure. Highly efficient swimming or flying animals use their propulsors (tails or wings) to generate vortices and then coordinate their body movements to take further advantage of those vortices in their wakes (Triantafyllou et al. 1993). The Strouhal number $(S t)$ is a dimensionless number that describes the spacing and size of shed vortices:

$$
S t=\frac{f A}{U}
$$

Optimal swimming efficiency is achieved within the range of $0.2<S t<0.4$, when staggered vortices form in unstable wakes where disturbances are amplified (Triantafyllou et al. 1993, Eloy 2012). We calculated $S t$ on the descent and ascent portion of each dive in low- and high-drag conditions to describe the patterns in the wake of the swimming whale, and to determine if $S t$ was within the optimal range in either condition.

We used the values of $C_{\mathrm{T}}$ and $S t$ for each dive descent and ascent to estimate the angle of attack $\left(\theta,{ }^{\circ}\right)$ and $\eta_{p}$ from flexible foil experiments and theory (Anderson et al. 1998, Hover et al. 2004; Fig. S2 in the Supplement). $\theta$ is the angle between the oncoming fluid velocity and the chord of the foil; lift is perpendicular to the velocity and drag along it. In flexible foils an estimated $\theta$ is obtained using an average chord direction. We assumed the tail to follow a symmetric 
sawtooth wave profile in Hover et al. (2004), (Fig. S2) except for where $S t<0.4$ where we assumed harmonic waves. Harmonic motion in heave and pitch is not optimal when $S t$ is high ( $>0.4$ ) because of the arctangent in the heave velocity term (Hover et al. 2004). At these values of $S t$, multi-harmonic or sawtooth motions provide far better efficiency and thrust. After estimating $\theta$ for each dive portion, we estimated $\eta_{\mathrm{p}}$ from $S t$ based on sawtooth and harmonic contours of $\theta$ from Hover et al. (2004, their Fig. 6) (Fig. S2). Points where $S t>1.6$ and $C_{\mathrm{T}} / S t^{2}>10$ were not included in the $\theta, \eta$, or power $(P, \mathrm{~W})$ estimates.

We used our derived estimates of propulsive efficiency to estimate 2 forms of $P$ separately for the descent and ascent of each dive in high and low drag conditions. Thrust power, $P_{\mathrm{T}}$, was estimated as:

$$
P_{\mathrm{T}}=\frac{D U}{\eta_{\mathrm{p}}}
$$

based on $\eta_{\mathrm{p}}$, alone, while overall power, $P_{\mathrm{O}}$, included metabolic efficiency $\left(\eta_{\mathrm{m}}\right)$ of 0.25 (Webb 1975b):

$$
P_{\mathrm{O}}=\frac{D U}{\eta_{\mathrm{p}} \times \eta_{\mathrm{m}}}
$$

\section{Statistical analysis}

We compared average descent and ascent rates within individuals between conditions with a Bonferroni corrected 2 -sample $t$-test $(\alpha=0.025)$. We expected that (1) both descent and ascent rates would be slower in the high-drag condition, but that (2) ascent speeds in the high-drag/high-buoyancy condition may not be reduced as much as descent speed, due to buoyant forces acting in the direction of travel. To determine whether fluke stroke timing differs with drag, we compared the duration of each fluke stroke and mean dive fluke stroke frequencies $(f)$ with 3-way ANOVA with effects of individual, loading condition, and dive phase (descent, bottom, ascent, and surface) and Tukey's post-hoc HSD (R Core Team 2015). We expected that higher drag conditions would result in shorter fluke stroke durations, or that fluke stroke rate would be greater in response to increased drag, especially on descent (the buoyancy-hindered direction). We compared theoretical drag loading conditions with a 2-sample $t$-test to determine whether disentanglement significantly reduced drag. We compared $C_{\mathrm{T}}, \eta_{\mathrm{i}}, \eta_{\mathrm{p}}, S t, P_{\mathrm{T}}$ and $P_{\mathrm{O}}$, estimated for Eg 3911, with 2-way ANOVA and Tukey's post-hoc HSD (R Core Team 2015) with effects loading condition and dive phase (descent, bottom, ascent, and surface). To determine whether $C_{\mathrm{T}}$ was affected by drug treatment, we fit the relationship between $C_{\mathrm{T}}$ and time with a linear regression model (MATLAB 2014).

\section{RESULTS}

\section{Case histories}

Eg 3911 was entangled in a total of $72 \mathrm{~m}$ of line, with 2 gangions (short lengths of moderate-weight line leading from traps to the groundline which connects the traps; McCarron \& Tetreault 2012) and 2 Scanmarin buoys of 42 and $45 \mathrm{~cm}$ diameter. At the time of the DTAG attachment on 15 January 2011, the entangling gear added an estimated $93 \mathrm{~N}$ of drag to the whale (Fig. 1A, Table 1). During this deployment, the disentanglement response team removed $50 \mathrm{~m}$ of gear, including one gangion and both buoys. The tag recorded through 4:20 $\mathrm{h}$ after the gear was removed, with a total deployment time of 6:11 h. Drug injection of a mixture of Midazolam and Butorphanol occurred 0:20 min after the tag was attached. The first 1:51 $\mathrm{h}$ of the recording were under high drag and buoyancy conditions, and the last $4: 20 \mathrm{~h}$ were low drag and buoyancy.

While the measured drag on a $34 \mathrm{~m}$ portion of the removed gear with buoys was $66 \mathrm{~N}$ at $1.5 \mathrm{~m} \mathrm{~s}^{-1}$ (van der Hoop et al. 2014b), an additional segment of the entangling gear was lost during disentanglement, expected to have added $8 \mathrm{~N}$ at $1.5 \mathrm{~m} \mathrm{~s}^{-1}$ (van der Hoop et al. 2016); the total drag of the removed gear was therefore $74 \mathrm{~N}$. Based on their dimensions, the buoys added $1058 \mathrm{~N}$ of positive buoyancy. The short amount of gear that remained on the whale added 19 $\mathrm{N}$ of drag, and the effect of buoyancy was likely negligible (Fig. 1C). This gear remained on Eg 3911 until she was discovered dead on 1 February 2011. The disentanglement effort reduced drag by $79.5 \%$.

On 16 February 2014, Eg 4057 was found entangled in $155 \mathrm{~m}$ of 3 -strand synthetic rope entering and exiting the left side of the mouth, with one end just above the eye and the other end trailing more than $30 \mathrm{~m}$ aft of the flukes before sinking out of view. The entangling gear was estimated to have added an average of $82 \mathrm{~N}$ of drag across speeds of 0.5 to $3.0 \mathrm{~m}$ $\mathrm{s}^{-1}$ (van der Hoop et al. 2016). The disentanglement team removed $104 \mathrm{~m}$ of line $(-24 \mathrm{~N})$ before attaching a satellite telemetry buoy $(+72 \mathrm{~N}$ drag, $+157 \mathrm{~N}$ buoyancy). The team then removed another $12.3 \mathrm{~m}$ of line $(-6 \mathrm{~N})$ before reattaching the telemetry buoy. The tag continued recording $1: 18 \mathrm{~h}$ following the addition of 


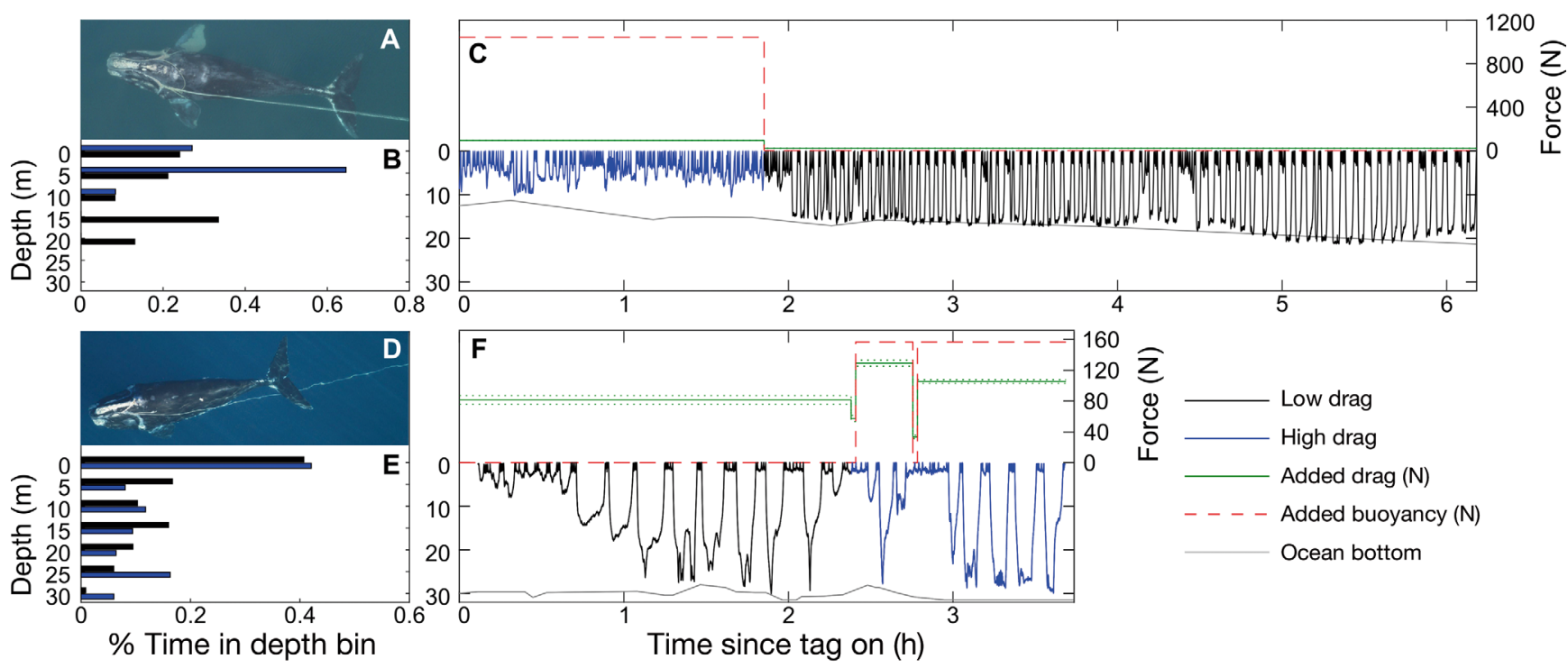

Fig. 1. Percentage of time spent at $(B, E)$ different depths and $(C, F)$ dive profiles from complete DTAG records of right whales (A) Eg 3911 and (D) Eg 4057 in low- and high- drag and buoyancy conditions. Drag (with 95\% CI) and buoyant forces are estimated from gear dimensions from van der Hoop et al. (2016) and from manufacturer information (see 'Materials and methods: Case histories' for details)

Table 1. Added drag and buoyant forces on right whales Eg 3911 and Eg 4057 before and after disentanglement response efforts. Blank cells represent no or negligible amounts of added buoyancy

\begin{tabular}{|lcccccc|}
\hline Whale & \multicolumn{2}{c}{ Drag } & & \multicolumn{2}{c|}{ Change } & \multicolumn{2}{c|}{ Buoyancy } \\
ID & \multicolumn{2}{c}{ before } & after & & in drag \\
iN) & $(\mathrm{N})$ & & before & after \\
& $(\mathrm{N})$ & $(\mathrm{N})$ & $(\mathrm{N})$ \\
\hline Eg 3911 & 93 & 19 & -79.5 & 1058 & \\
Eg 4057 & 82 & 124 & +51.2 & & 157 \\
\hline
\end{tabular}

the telemetry buoy. Overall, $116 \mathrm{~m}$ of rope was removed, reducing drag by $30 \mathrm{~N}$; however, the attachment of the telemetry buoy resulted in a $51.2 \%$ increase in drag over the original entangled condition, totalling $124 \mathrm{~N}$ (Fig. 1F). Eg 4057's tag deployment was $3: 34 \mathrm{~h}$ long; the first $2: 16 \mathrm{~h}$ with low drag and buoyancy and the latter 1:18 $\mathrm{h}$ with high drag and buoyancy (Fig. 1C,F). The telemetry buoy and almost all of the entangling gear were successfully removed the following day. The whale was sighted and confirmed gear-free 20 April 2015 in Cape Cod Bay.

\section{Dive parameters}

Eg 3911 completed 154 dives over the 6:11 h deployment period, with 101 and 53 dives in lowand high-drag conditions, respectively. Significant changes in diving behavior of Eg 3911 associated with disentanglement have been previously described (van der Hoop et al. 2014b). Eg 4057 made a total of 20 dives over the 3:34 h deployment, with 12 and 8 dives under low- and high-drag conditions, respectively, to a depth of 5 to $30 \mathrm{~m}$ (Fig. 1F). In contrast to Eg 3911, the depth distribution of Eg 4057 was very similar between low- and high-drag conditions (Fig. 1E). Tag data therefore indicate variable responses in diving behavior between these 2 individuals.

The observed changes in ascent and descent rates of Egs 3911 and 4057 in response to drag and buoyancy were different (Table 2). Eg 3911 swam significantly slower in high-drag conditions, with descents on average $0.32 \mathrm{~m} \mathrm{~s}^{-1}(46 \%)$ and ascents $0.14 \mathrm{~m} \mathrm{~s}^{-1}$ $(32 \%)$ slower than ascents. Observed speeds were greater than the expected reduction necessary to maintain low-drag drag forces under the high-drag condition on descents $(67 \%)$ and ascents (49\%; Table 2). Eg 4057 descended significantly faster in high-drag conditions (by $0.07 \mathrm{~m} \mathrm{~s}^{-1} ; 24 \%$ ). There was no detectable difference in ascent rate (Table 2). Observed speeds were considerably faster than those expected if Eg 4057 were attempting to maintain the same drag forces as would be experienced in the low-drag condition.

\section{Kinematic parameters}

We derived kinematic parameters from all 154 dives of Eg 3911. Due to movement of the tag on Eg 
4057, we could only derive fluke stroke kinematics for 17 dives in total, 11 in low-drag conditions and 6 in high-drag conditions. The number of individual fluke strokes in various conditions and dive phases are shown in Fig. 2.

There were significant, interactive effects on dive phase and drag condition on individual fluke strokes in these 2 whales (Fig. 2). The duration of the fluke stroke cycle was significantly shorter in Eg 3911 compared to Eg $4057\left(F_{1,50155}=9866.8, \quad p<0.0001\right.$; Fig. 2A-H vs. Fig. 2I-P). Their response to drag condition was significantly different (Whale $\times$ Condition, $\left.F_{1,50155}=3113.4, \mathrm{p}<0.0001\right)$ whereby in Eg 3911, individual fluke strokes were significantly longer in the high-drag condition compared to low-drag condition (Tukey's HSD p < 0.0001; Fig. 2A-D vs. Fig. 2E-H). Although this result is statistically significant, it is likely not biologically significant, with a difference of 0.09 (95\% CI 0.05-0.13) s. In contrast, Eg 4057 swam with significantly shorter fluke strokes in high-drag (3.95 $\pm 0.71 \mathrm{~s})$ compared to low-drag conditions (5.42 $\pm 0.16 \mathrm{~s}$; Tukey's HSD $\mathrm{p}<0.0001$; Fig. $2 \mathrm{M}-\mathrm{P}$ vs. Fig. 2I-L). Dive phase had a significant effect on fluke stroke duration, especially in high-drag conditions. Fluke strokes were significantly shorter during the bottom phase of dives in both whales (Fig. 2B,F,J,N).

The longer fluke stroke durations observed for $\mathrm{Eg}$ 4057 in low-drag conditions, and especially on dive descents (e.g. Fig. 2I), corresponded with glides. Both individuals performed fewer glides in high-drag conditions (Eg 4057: $\mathrm{n}=5,2.6 \times 10^{-3}$ glides $\mathrm{min}^{-1}$; Eg 3911: $\mathrm{n}=1,1.5 \times 10^{-4}$ glides $\mathrm{min}^{-1}$ ) compared to in low-drag (Eg 4057: $\mathrm{n}=40,4.9 \times 10^{-3}$ glides $\mathrm{min}^{-1}$; $\mathrm{Eg}$ 3911: $\mathrm{n}=7,4.5 \times 10^{-4}$ glides $\mathrm{min}^{-1}$ ) conditions (Fig. 3).

Related to fluke stroke duration, but averaged over each dive phase for all dives, $f$ was significantly different between the 2 whales (3-way ANOVA, $F_{1,642}=$ 186.9, p < 0.0001; Fig. 4); across all dive phases, $f$ of Eg $3911(0.296 \pm 0.072 \mathrm{~Hz})$ was $40 \%$ greater than that of $\mathrm{Eg} 4057$ (0.178 $\pm 0.058 \mathrm{~Hz}) . f$ also differed between dive phases (3-way ANOVA, $F_{3,642}=26.55, \mathrm{p}<$ 0.0001 ), being significantly greater at the surface $(0.326 \pm 0.128 \mathrm{~Hz})$ compared to all other dive phases (Tukey's HSD p $<0.0001$ for each phase; Table 3). Average fluke stroke rate did not, however, appear to differ between low- and high-drag conditions $\left(F_{1,642}=\right.$ 0.3505, p = 0.554; Fig. 4).

Mean body pitch amplitudes were variable across dive phases and drag conditions (Figs. 2 \& 3). We could not make quantitative comparisons of amplitude for Eg 4057 due to tag movement during the deployment, or between the tags due to differences in tag placement. In both animals, fluke strokes appeared to be more variable in duration and shape in high drag/buoyancy (Fig. 3B,D vs. A,C), and during bottom and ascent phases (Fig. 2B,F,N vs. C, G,O).

\section{Thrust, efficiency and power}

We estimated drag on non-entangled Eg 3911 to be 10-463 N across speeds of $0.3-2.5 \mathrm{~m} \mathrm{~s}^{-1}$ (Fig. S1 in the Supplement). When entangled, drag on Eg 3911 was significantly (mean $\pm \mathrm{SD}, 230 \pm 228 \%$ ) greater, ranging from 118-909 N (2-sample $t$-test; $t=10.8881$, $\mathrm{p}<0.0001$ ). Following disentanglement, drag was significantly reduced by on average $53 \pm 7 \%$, to $37-489$ $\mathrm{N}$ across speeds (Fig. $\mathrm{S} 1 ; t=-9.6970, \mathrm{p}<0.0001$ ).

Both drag condition and dive phase had a significant effect on $C_{\mathrm{T}}$. When entangled, $C_{\mathrm{T}}$ during dive descents was $0.164 \pm 0.082$ and ascents were significantly greater than following disentanglement $(0.311$ \pm 0.135 ; 2 -way ANOVA, $F_{1,304}=83.10, \mathrm{p}<0.0001$; Fig. 5A). Eg 3911's disentanglement procedure significantly reduced thrust coefficients on descent and ascent by 3.91- and 3.99-fold, to $0.042( \pm 0.012)$ and $0.078( \pm 0.018)$, respectively (2-way ANOVA, $F_{1,305}=$ $425.8, \mathrm{p}<0.0001$; Fig. 5A). Because a portion of gear

Table 2. Mean $( \pm \mathrm{SD})$ dive descent and ascent rates for right whales Eg 3911 and Eg 4057 in low- and high-drag conditions, with the \% change in observed speeds between low- and high-drag conditions and the expected reduction in speed (in $\mathrm{m} \mathrm{s}^{-1}$ and \%) to maintain the same power output as in low drag. Values for $t$ statistic and p from 2-sample $t$-tests are included, with Bonferonni-corrected $\alpha=0.025$

\begin{tabular}{|c|c|c|c|c|}
\hline & \multicolumn{2}{|c|}{$\longrightarrow$ Eg $3911(\mathrm{n}=154)$} & \multicolumn{2}{|c|}{$\longrightarrow \operatorname{Eg} 4057(\mathrm{n}=20)$} \\
\hline & Descent rate $\left(\mathrm{m} \mathrm{s}^{-1}\right)$ & Ascent rate $\left(\mathrm{m} \mathrm{s}^{-1}\right)$ & Descent rate $\left(\mathrm{m} \mathrm{s}^{-1}\right)$ & Ascent rate $\left(\mathrm{m} \mathrm{s}^{-1}\right)$ \\
\hline Low drag & $0.68( \pm 0.22)$ & $0.44( \pm 0.13)$ & $0.29( \pm 0.14)$ & $0.14( \pm 0.11)$ \\
\hline High drag & $0.36( \pm 0.12)$ & $0.30( \pm 0.09)$ & $0.36( \pm 0.12)$ & $0.21( \pm 0.10)$ \\
\hline$\%$ change observed & -46 & -32 & +24 & +50 \\
\hline$t, \mathrm{p}$ & $t=-9.77, \mathrm{p}<0.0001$ & $t=-7.32, \mathrm{p}<0.0001$ & $t=3.02, \mathrm{p}=0.0073$ & $t=1.42, \mathrm{p}=0.1733$ \\
\hline Expected speed, high drag & $0.22( \pm 0.10)$ & $0.11( \pm 0.05)$ & $0.08( \pm 0.04)$ & $0.07( \pm 0.04)$ \\
\hline$\%$ change expected & -67 & -49 & -56 & -53 \\
\hline
\end{tabular}



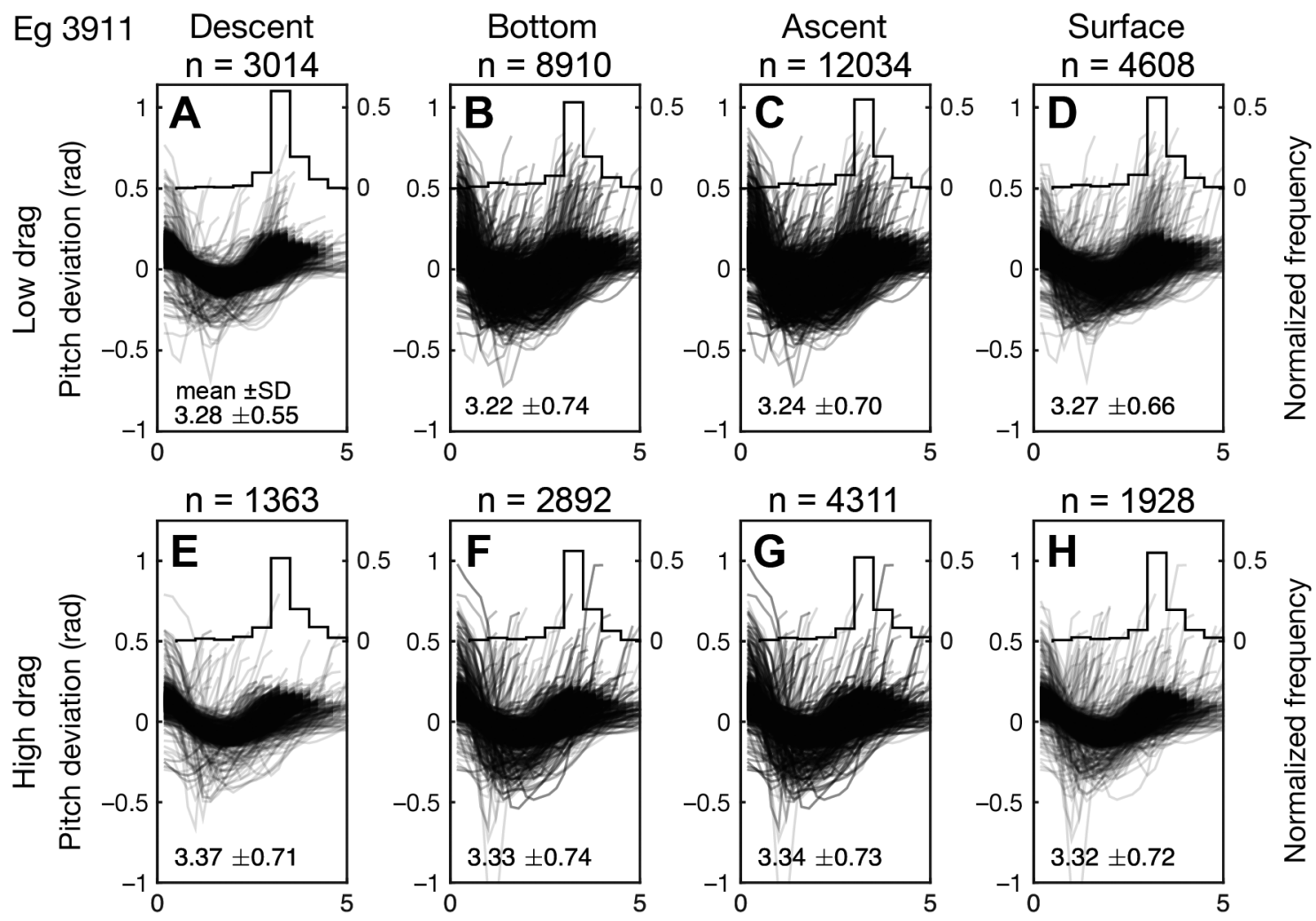

Eg $4057 \quad n=982$
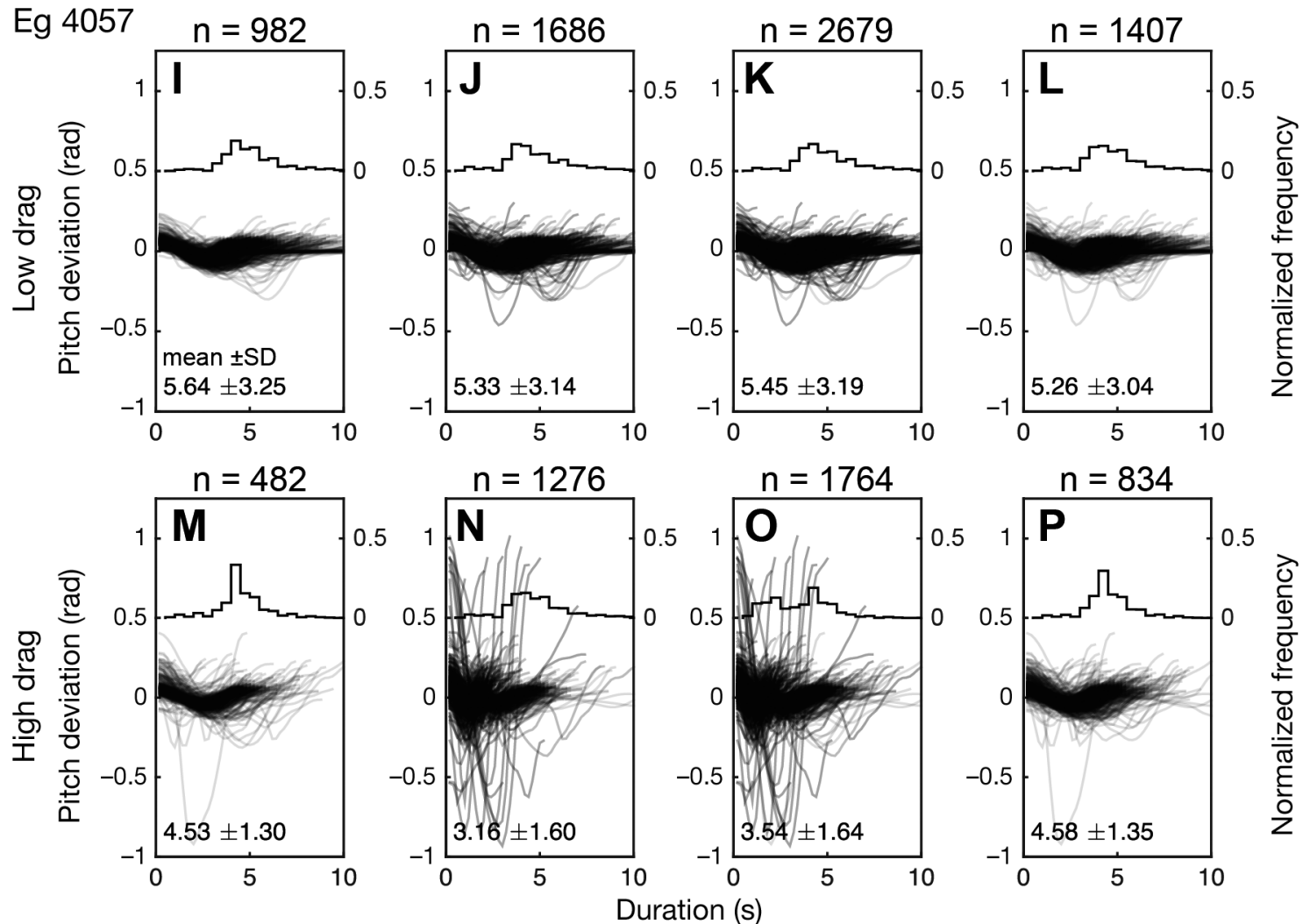

Fig. 2. Right whales show different fluke stroke patterns between individuals, dive phases and drag conditions. Individual fluke strokes measured from pitch deviation (radians) in (A-D, I-L) low- and (E-H, M-P) high-drag conditions during the dive $(A, E, I, M)$ descents, (B, F, J, N) bottom, (C, G, K, O) ascents and (D, H, L, P) surface periods for 2 right whales (Eg 3911 A-H; Eg 4057 I-P). Histograms show the frequency of observations of each duration, normalized by the total number of observations. Mean \pm SD fluke stroke duration are shown in the bottom left and sample sizes (n) are denoted above each panel 


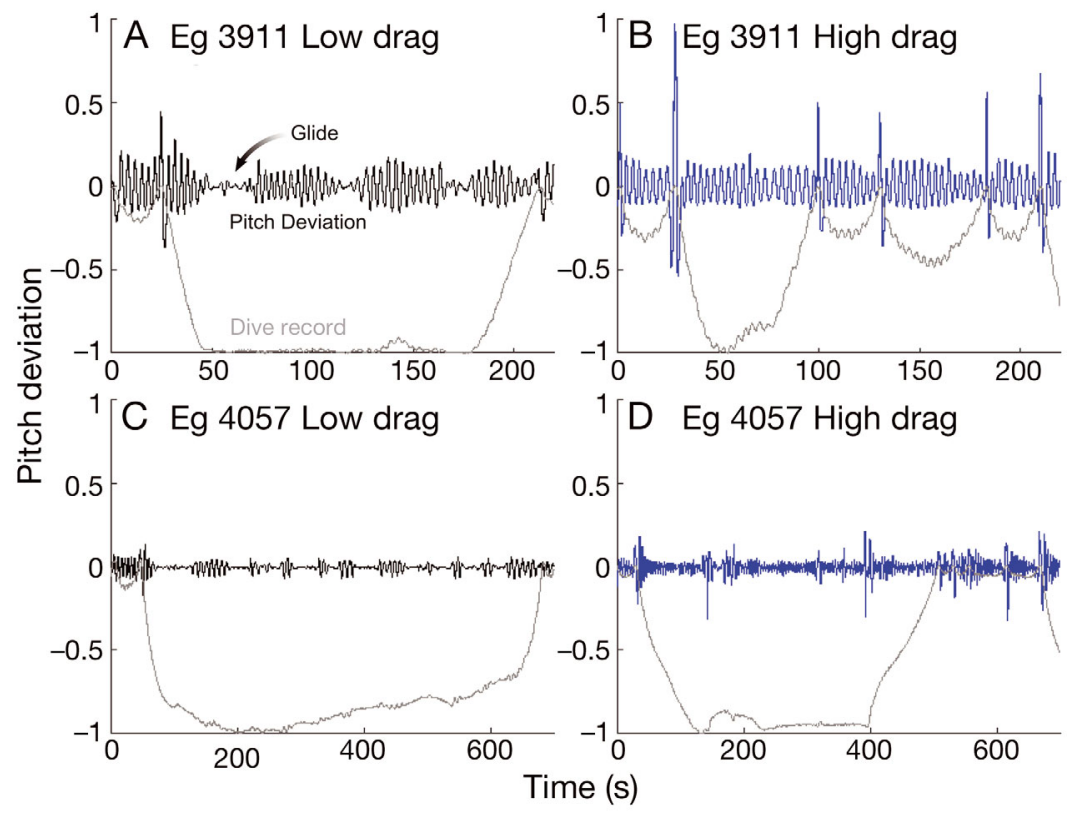

Fig. 3. Pitch deviation (radians), showing individual fluke strokes and periods of gliding, in $(\mathrm{A}, \mathrm{C})$ low-drag (black line) and $(\mathrm{B}, \mathrm{D})$ high-drag (blue line) conditions in 2 right whales (A, B: Eg 3911 and C, D: Eg 4057). Relative dive depth (normalized to max depth $=-1$ ) is shown in grey lines for context

remained on the whale, $C_{\mathrm{T}}$ when disentangled was still on average 1.31- and 1.53-fold greater than estimated for the non-entangled condition on descent

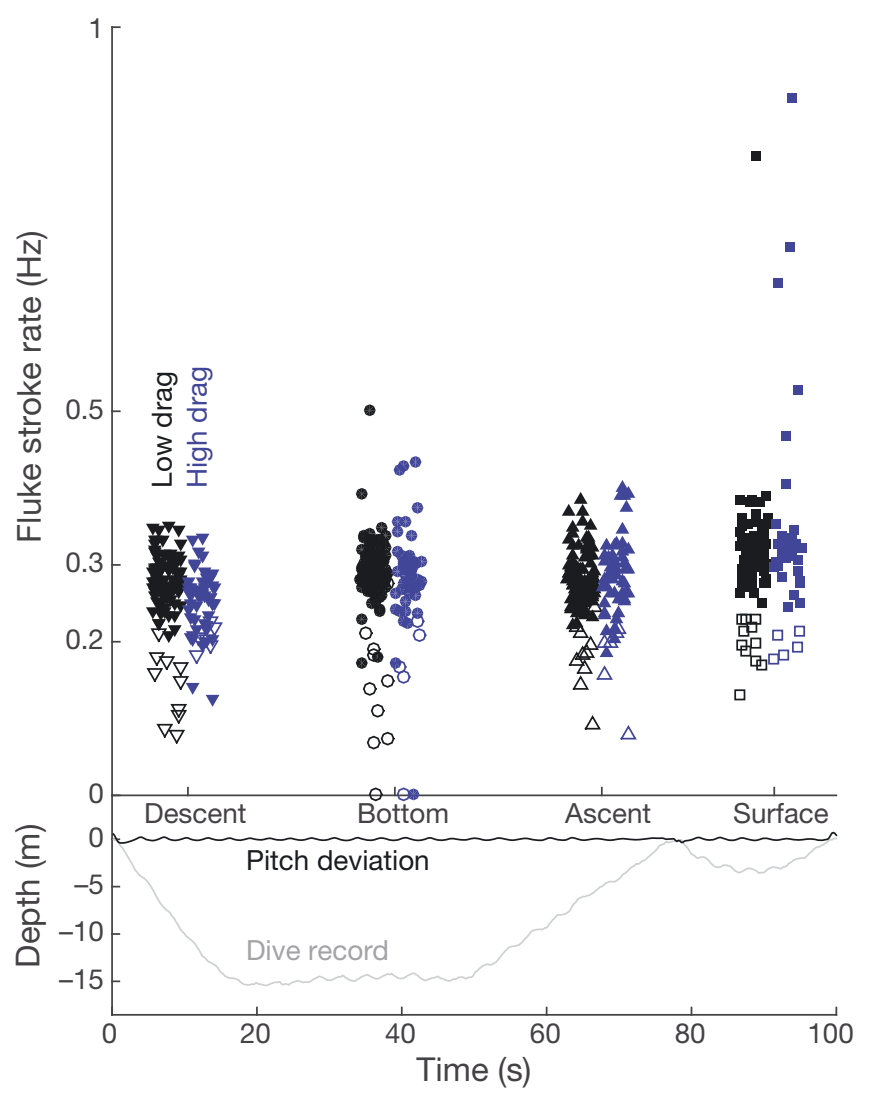

$(0.047 \pm 0.002)$ and ascent $(0.051 \pm$ 0.004; Fig. 5A). $C_{\mathrm{T}}$ was almost always greater during each dive's ascent than on descent, and is confined to a very narrow range in low-drag conditions (Fig. S3A in the Supplement). In highdrag conditions, $C_{\mathrm{T}}$ was much more variable (Fig. S3A) and showed a significant decrease with time, prior to disentanglement and following drug injection (Fig. S3B). Specifically, $C_{\mathrm{T}}$ on descent $\left(C_{\mathrm{T}, \mathrm{desc}}\right)$ and ascent $\left(C_{\mathrm{T}, \mathrm{asc}}\right)$ as: $C_{\mathrm{T}, \mathrm{desc}}=0.28-\left(2.97 \times 10^{-5}\right) \times$ time $(8)$ (with time in $\mathrm{s}_{;} \mathrm{R}^{2}=0.34, \mathrm{p}<0.0001$ ), and

$$
C_{\mathrm{T}, \mathrm{asc}}=0.41-\left(2.53 \times 10^{-5}\right) \times \text { time }
$$

(with time in $\mathrm{s}_{;} \mathrm{R}^{2}=0.12, \mathrm{p}<0.0231$ ). When entangled, $\eta_{\mathrm{i}}$ was $96.3 \pm 1.7$ and $93.4 \pm 2.4 \%$ on descent and ascent, respectively (Fig. 5B). After disentanglement, $\eta_{\mathrm{i}}$ for descent and ascent increased to $99.0 \pm 0.3$ and $98.1 \pm$ $0.4 \%$, respectively (2-way ANOVA, $F_{1,305}=526.8, \mathrm{p}<0.0001$; Fig. 5B). For the non-entangled whale, ideal efficiency was $99.2 \pm 0.1 \%$ on descent and $98.8 \pm 0.1 \%$ on ascent (Fig. 5B).

The St was significantly lower on descent compared to ascent (Fig. 6A; 2-way ANOVA, $F_{1,305}=$ $11.13, \mathrm{p}<0.0010$ ) but we detected no significant difference between low and high drag (Fig. 6A; $F_{1,305}=$ 2.636, $\mathrm{p}=0.1056)$. St on descents was $0.726 \pm 0.257$ compared to $0.833 \pm 0.292$ on ascent. Similarly, $\eta_{p}$ was significantly higher on descent (0.19 \pm 0.09$)$ compared to ascent $\left(0.14 \pm 0.09\right.$; Fig. $6 B_{\text {; }}$ Table 4 ; 2 -way ANOVA, $\left.F_{1,294}=15.93, \mathrm{p}<0.0001\right)$, but we detected no difference as drag was decreased after disentanglement $\left(F_{1,294}=0.1413, \mathrm{p}=0.7073\right.$; Table 4$)$. $P_{\mathrm{T}}$ was 1.25 -fold greater on dive ascents compared to descents (Fig. 7; Table 4; 2 -way ANOVA, $F_{1,294}=$ 6.0186, $\mathrm{p}=0.0147$ ). Drag from entangling gear significantly increased thrust power, by 1.8- and 1.2-fold on descent and ascent, respectively (Fig 7 ; Table $\left.4 ; F_{1,294}=13.33, \mathrm{p}=0.0003\right)$.

Fig. 4. Average fluke stroke rates of right whales Eg 3911 (closed symbols) and Eg 4057 (open symbols) at different dive phases and in low-drag (black) and high-drag (blue) conditions. A representative dive profile (grey line) and pitch record (black line) illustrate the periods over which fluke stroke rates are calculated: descent (downward triangles), bottom (circles), ascent (upward triangles) and surface (squares) 
Table 3. Mean (SD) fluke stroke cycle duration and dive-phase averaged fluke stroke rates for descent, bottom, ascent, and surface portions of the dive records of 2 right whales, Eg 3911 and Eg 4057

\begin{tabular}{|c|c|c|c|c|c|c|c|c|}
\hline \multirow{2}{*}{$\begin{array}{l}\text { Drag } \\
\text { condition }\end{array}$} & \multicolumn{2}{|c|}{$\longrightarrow$ Descent $\longrightarrow$} & \multicolumn{2}{|c|}{ Bottom } & \multicolumn{2}{|c|}{ - Ascent } & \multicolumn{2}{|c|}{ Surface } \\
\hline & Eg 3911 & Eg 4057 & Eg 3911 & Eg 4057 & Eg 3911 & Eg 4057 & Eg 3911 & Eg 4057 \\
\hline \multicolumn{9}{|c|}{ Duration (s) } \\
\hline Low & $3.28(0.55)$ & $5.64(3.25)$ & $3.22(0.74)$ & $5.33(3.14)$ & $3.24(0.70)$ & $5.45(3.19)$ & $3.27(0.66)$ & $5.26(3.04)$ \\
\hline High & $3.37(0.71)$ & $4.53(1.30)$ & $3.33(0.74)$ & $3.16(1.60)$ & $3.34(0.73)$ & $3.54(1.64)$ & $3.32(0.72)$ & $4.58(1.35)$ \\
\hline \multicolumn{9}{|l|}{ Rate (Hz) } \\
\hline Low & $0.282(0.029)$ & $0.153(0.057)$ & $0.295(0.037)$ & $0.152(0.087)$ & $0.285(0.033)$ & $0.188(0.047)$ & $0.335(0.120)$ & $0.198(0.031)$ \\
\hline High & $0.253(0.041)$ & $0.206(0.015)$ & $0.289(0.063)$ & $0.171(0.094)$ & $0.288(0.047)$ & $0.176(0.052)$ & $0.362(0.139)$ & $0.195(0.017)$ \\
\hline
\end{tabular}

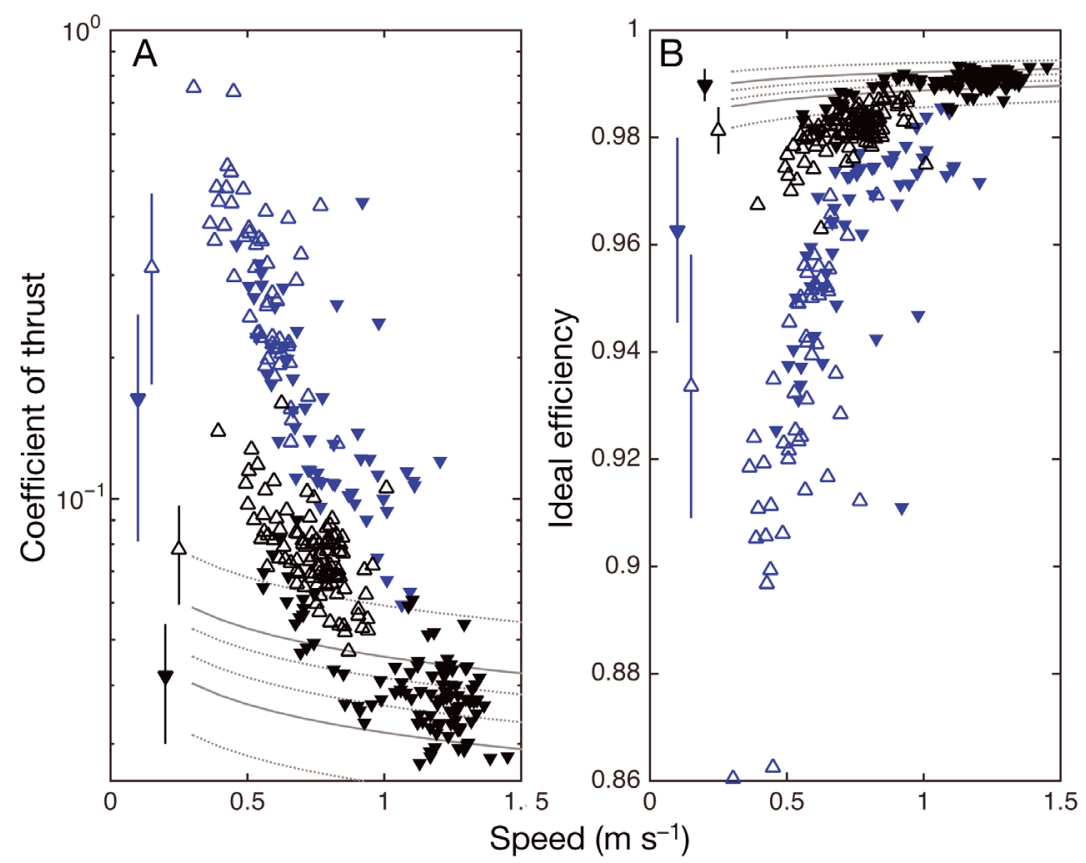

Fig. 5. Effect of disentanglement on thrust coefficients $\left(C_{\mathrm{T}}\right)$ and ideal efficiency $\left(\eta_{\mathrm{i}}\right)$ for an entangled right whale Eg 3911. (A) $C_{\mathrm{T}}$ and (B) $\eta_{\mathrm{i}}$ were calculated for each descent (inverted filled triangles) and ascent (open triangles) of entangled (blue) and disentangled (black) dives. Estimates of $C_{\mathrm{T}}$ and $\eta_{\mathrm{i}}$ for the non-entangled condition are shown for reference (grey lines); grey dashed lines represent uncertainty for oscillation and gear drag estimates. Mean values (error bars $=\mathrm{SD}$ ) are presented for each condition and dive portion. Note the $\log y$-axis in $(\mathrm{A})$

\section{DISCUSSION}

Animals, including humans, constantly navigate an energy landscape where kinematics or gait parameters are tuned to minimize metabolic cost in response to changing constraints (Bertram 2005, 2015, Selinger et al. 2015). Swimmers tune their fluke strokes to address trade-offs between thrust generation and efficiency to optimize performance, especially in response to changes in their natural force balance. Laboratory studies on humans and other animals are able to apply external forces in order to understand motor reorganization strategies and motor control (Bonnard \& Pailhous 1991). Similarly, in this study we attached fine-scale movement tags to 2 right whales that were entangled in fishing gear; recording continued while the forces on the whales were decreased (Eg 3911, via removal of the fishing gear) and increased (Eg 4057, via attachment of a satellite telemetry tracking buoy). Many of the changes in behavior we observed were individually specific; swimming kinematics were modulated in response to high drag and buoyant forces associated with entanglement in fishing gear, but not necessarily consistently between animals. Observed changes in gait parameters and swimming speed can significantly affect thrust production and efficiency, but may not be applicable to all entangled whales.

\section{Diving behavior}

While the diving behavior of $\mathrm{Eg}$ 3911 was significantly affected by drag and buoyancy (Fig. 1C, van der Hoop et al. 2014b), such a striking difference was not observed in Eg 4057. As both whales were tagged on the breeding grounds in Florida, similar diving behaviors were expected in comparable water depths, times of year and point in the annual migration pattern (e.g. see McGregor 2010). The variable responses in dive patterns may be attributed to the difference in forces experienced by the individuals: while drag forces were comparable (93 N and $105 \mathrm{~N}$, respectively), the buoyant forces on Eg 3911 were an order of magnitude greater than for Eg 4057 (1058 N and $157 \mathrm{~N}$, 

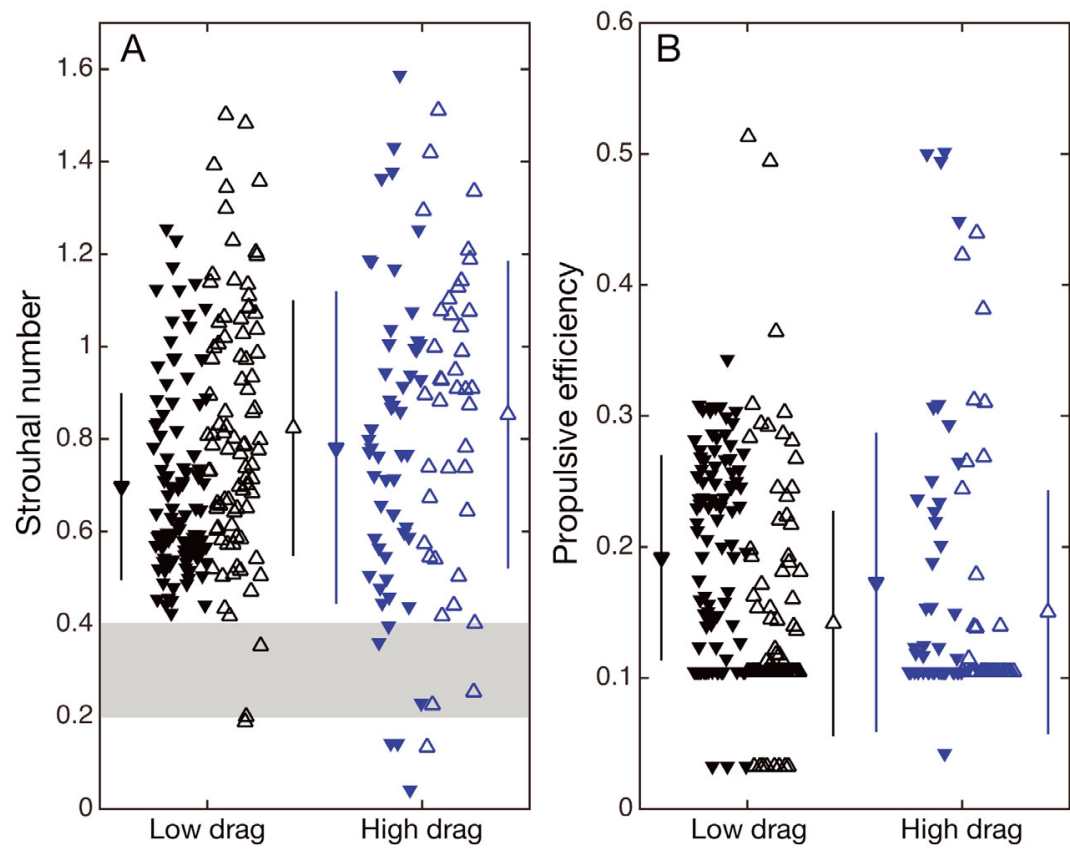

Fig. 6. (A) Strouhal number (St) and (B) propulsive efficiency $\left(\eta_{\mathrm{p}}\right)$ during periods of dive descent (filled inverted triangles) and ascent (open triangles) and in low-drag (black, disentangled) and high-drag (blue, entangled) conditions for right whale $\mathrm{Eg}$ 3911. Mean values (error bars = SD) are presented for each condition and dive portion. The shaded region represents the optimal range of $0.2<S t<0.4$

Table 4. Propulsive efficiency, thrust and overall power of right whale Eg 3911 in low- and high-drag and buoyancy conditions, on descents and ascents of dives to $>5 \mathrm{~m}$

\begin{tabular}{|c|c|c|c|c|}
\hline & \multicolumn{2}{|c|}{ Low drag } & \multicolumn{2}{|c|}{- High drag } \\
\hline & Descent & Ascent & Descent & Ascent \\
\hline \multicolumn{5}{|c|}{ Propulsive efficiency } \\
\hline Mean (SD) & $0.19(0.08)$ & $0.14(0.09)$ & $0.17(0.11)$ & $0.15(0.09)$ \\
\hline Max & 0.34 & 0.51 & 0.50 & 0.44 \\
\hline \multicolumn{5}{|c|}{ Thrust power (W) } \\
\hline Mean (SD) & 399 (373) & $604(553)$ & $723(569)$ & $706(287)$ \\
\hline Max & 2762 & 2762 & 3858 & 1215 \\
\hline \multicolumn{5}{|c|}{ Overall power (W) } \\
\hline Mean (SD) & $1596(1494)$ & $2416(2215)$ & 2893 (2278) & 2824 (1149) \\
\hline Max & 11051 & 11051 & 15435 & 4862 \\
\hline
\end{tabular}

respectively, Fig. 1C,F, Table 1). Eg 3911's more abrupt response may be due to relative change in force balance if feedback to loading is intensity dependent, as it is in humans and other vertebrates (Duysens et al. 2000). For both tagged right whales, the length of the tether to the buoys was greater than the maximum dive depth $(\mathrm{Eg} 3911=\sim 1 \mathrm{~m}$ tether; $\mathrm{Eg}$ $4057=\sim 33 \mathrm{~m}$ tether). However, visual observations of Eg 4057 described the telemetry buoy being pulled underwater during dives (K. Jackson pers. comm.). The short tag deployment durations, especially for
Eg 4057, make it difficult to assess changes in diving behavior associated drag and buoyancy. Future disentanglement operations should continue attaching tags to collect similar data which will enable additional comparisons of individual responses to entanglement drag.

Differences in body condition between the whales are also relevant to differences in dive responses. Because the total buoyancy of these individuals is unknown, it is difficult to know just how the ratio of body to added buoyancy may affect their diving behaviour. Eg 3911 was 20\% thinner than mesomorphic right whales (van der Hoop et al. 2014b), and was therefore likely negatively buoyant; however, the entangling gear added a considerable amount of positive buoyancy. If Eg 3911 were to take advantage of added buoyant force, we would expect little change in dive ascent rate, and significantly greater fluke stroke kinematics and thrust on descent in high drag. Contrary to this expectation, $C_{\mathrm{T}}$ and $P_{\mathrm{T}}$ were significantly greater on ascent than descent in high-drag conditions (Figs. 5A \& 7, Fig. S3A in the Supplement). The only observation suggesting buoyancyaided ascents was that gear removal led to increases in descent speeds by $46 \%$ and ascent speeds by $32 \%$; gear had reduced speeds in both directions, but more so in the direction opposite the net force. Eg 3911 did not slow as much as was expected to maintain drag forces (Table 2). The additional buoyancy should have been more inhibitive for Eg 4057 on descent, as the whale was positively buoyant (Nowacek et al. 2001). However, Eg 4057 was able to reach comparable depths in both low- and high-drag and buoyancy conditions and swam at greater speeds in high vs. low drag (Table 2); Eg 4057 did not slow down to reduce power output in either direction.

It is important to acknowledge that Eg 3911 was treated with a mixture of Midazolam and Butorphanol 20 min $(0.34 \mathrm{~h})$ after the DTAG was attached in order to facilitate the disentanglement procedure (Moore et al. 2010, van der Hoop et al. 2014b). Mida- 


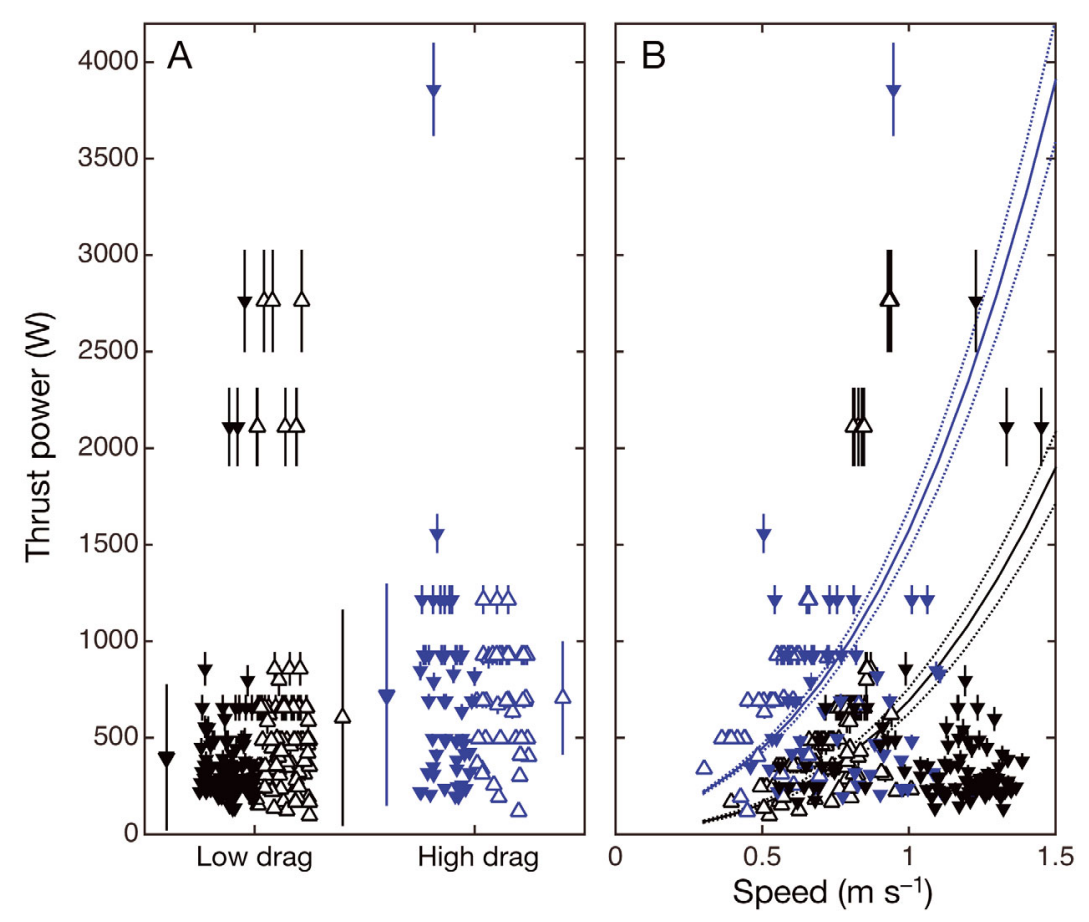

Fig. 7. (A) Thrust power on dive descent (filled inverted triangles) and ascent (open triangles) and in low-drag (black, disentangled) compared to high-drag (blue, entangled) conditions for right whale Eg 3911. (B) Thrust power estimates derived from swimming kinematics (symbols) approximate theoretical calculations related to speed (lines). Dotted lines represent uncertainty in oscillation and gear drag estimates

zolam produces reliable hypnosis, amnesia, and antianxiety effects (Reves et al. 1985), while Butorphanol is an analgesic (Pircio et al. 1976). Thus a mix of these drugs was appropriate for an entangled whale that had undergone months of pain from tissue constriction and laceration, with granulation and scarring, and increased work from the drag of the entanglement. The short-term effect of this drug mixture as it is absorbed from an intra-muscular injection over a period of approx. 30 min would be to increasingly lessen pain, forget past stress, and reduce anxiety. Thus the animal would be likely to resume a more 'normal' (vs. pain-impaired) gait for the duration of effective blood levels of the drug mixture, which might last for an hour or more. During this time, fluke stroke amplitude and vertical speed increased, leading to a slight reduction in thrust coefficient and an increase in swimming efficiency (Fig. S3B). Further, van der Hoop et al. (2014b) found significantly higher fluke stroke rate and RMS fluke stroke energy after injection, but still prior to disentanglement. In a different right whale (Eg 3311), a similar drug mixture led to a significant increase in respiratory frequency an hour after injection, along with increases in swimming speed and a marked reduction of boat evasion (Moore et al. 2010). Together, these data suggest that anti-anxiety and analgesic drugs likely reduce pain to enable standard locomotion at higher speeds.

\section{Kinematic responses}

It was expected that, similar to bowhead whales (Simon et al. 2009), right whales would reduce swimming speeds and adopt continuous swimming gaits (i.e. increase fluke stroke frequency) in higher-drag scenarios; fluke stroke duration would therefore reflect the relative strength of opposing forces for the 2 whales. Both whales were subject to higher drag when swimming at the surface (Hertel 1969, Webb 1975b), resulting in shorter fluke strokes and higher fluke stroke rates (Figs. 2 \& 4). For Eg 3911, it was expected that fluke strokes would be longer on descent, as the animal was likely negatively buoyant, and shorter on ascents. The opposite was expected for Eg 4057, a healthy and likely positively buoyant individual: fluke stroke durations would be shorter on descent compared to ascent. Overall, drag loading should shorten fluke strokes, especially in the direction opposing movement. While the overall expectation of shorter fluke stroke durations with drag loading was observed for Eg 4057 (Fig. 2I-L vs. M-P), the expected pattern of fluke stroke duration with respect to dive phase was not observed. If whales were taking advantage of added buoyancy, the inverted pattern of what was observed in entangled Eg 4057 would be expected: shorter on descent and higher on ascent (Fig. 2I vs. K). Again, it does not appear that these whales were taking advantage of the buoyancy added by the entangling gear. This may be because the buoyancy was not acting at the center of mass, but instead was trailing 15 to $30 \mathrm{~m}$ behind the whales, often deeper than their dive depths.

The significantly longer fluke strokes in Eg 4057, especially in low-drag conditions, correspond to periods of gliding. Both individuals showed fewer instances of gliding in high-drag conditions, consistent with more propulsion to counter greater drag forces, as has been observed in other balaenids during highdrag filter feeding (Simon et al. 2012). Alternative 
gaits may not always be an option (Maresh et al. 2014), and these data suggest that despite considerable drag loading, whales still appear to use stroke and glide swimming when entangled (Eg 4057; Fig. $3 C, D)$, albeit less frequently, and are able to exploit some cost-effective swimming techniques.

There are a number of trade-offs that must be balanced when altering kinematics. For example, thrust increases, but, beyond a certain threshold, efficiency decreases with fluke-stroke frequency (Daniel 1991) and, again, beyond a certain threshold, with the angle of attack (Chopra \& Kambe 1977). Swimming animals often increase fin-beat frequency in response to changes in force balance (Skrovan et al. 1999, Williams 1999, Cornick et al. 2006, Aoki et al. 2011). Adjusting frequency instead of amplitude may be a strategy to reduce body distortion required for large-amplitude movements that would further increase drag (Fish et al. 2003); there may also be limitations on the amount of work per stroke (Lovvorn et al. 2004). Changes in amplitude are less common in the literature compared to frequency, but may be particularly useful in generating high thrust when especially needed, such as for rapid accelerations (Fish et al. 2014) or at the initiation of dives (Fig. 3B).

\section{Changes in efficiency}

Whales swim by oscillating their tails and body, the rate, amplitude and angle of which can be altered to optimize propulsive efficiency. The relationship between these kinematic parameters and swimming speed is represented by St (Eq. 5), where the greatest swimming efficiencies occur in the range $0.2<S t<$ 0.4 (Triantafyllou et al. 1993, Eloy 2011). We expected that frequency, amplitude and speed would be adjusted to maintain efficiency or a given $S t$ in low- and high-drag conditions. Some swimmers are able to compensate and maintain $S t$ (Noren et al. 2011, Nudds et al. 2014), whereas others have significantly greater and suboptimal $S t$ with drag loading (Lang \& Daybell 1963; Methling et al. 2011). In this study, the St of right whale Eg 3911 was significantly lower on descent than ascent, but did not change significantly following removal of entangling fishing gear (Fig. 6A). Propulsive efficiencies were significantly greater on descents vs. ascents, but were maintained between drag conditions. Eg 3911 appeared to be able to alter kinematics to compensate for the effects of drag loading to maintain similar, although sub-optimal, propulsive efficiency.
Individual and context-specific compensatory strategies occur on a range of temporal scales. Ants and other load-carrying insects show plasticity in their step patterns and leg positions (Zollikofer 1994). Humans respond on the order of seconds to constraints in step frequency, stride length, or walking speed (Bertram 2005) and converge on new energetic optima within minutes to realize seemingly small savings in energetic cost $(<5 \%$; Selinger et al. 2015). High-heel wearers adjust their movements systematically with heel height to maintain heart rate and oxygen consumption (Ebbeling et al. 1994). Prior exposure to specific limitations, e.g. experienced vs. inexperienced high-heel wearers (Opila-Correia, 1990) or previous study subjects (Selinger et al. 2015) enhances the speed and plasticity of individual responses. Whales and other marine mammals make small gait changes in response to repetitive and transient actions, such as reducing thrust production in the buoyancy-aided direction on dives (Nowacek et al. 2001, Aoki et al. 2011, Miller et al. 2012, Adachi et al. 2014, Nousek-McGregor et al. 2014). These case studies show yet another condition in which animals perceive changes in movement constraints over the course of seconds to minutes, here resulting from disentanglement response, and alter their movement accordingly (Duysens et al. 2000).

Compensation can also occur over the long term as whales are entangled for months to years. Certain postural diseases (e.g. flatback syndrome; Sarwahi et al. 2002) lead to specific gait modifications to reduce the cost of transport but can cause abnormal joint loading and eventual degeneration. Similarly, as amputees alter their biomechanics while establishing a prosthetic gait, loading imbalances lead to osteoarthritis of the intact limb and osteopenia due to insufficient loading of the residual limb (Gailey et al. 2008). Sustained compensation may be a mechanism for musculoskeletal deformations observed in entangled animals.

Trauma and consistent compensation for the disproportionate forces and moments associated with chronic entanglement are assumed to have deformed the developing vertebrae in a juvenile right whale, CALO0901, to the point of severe scoliosis that led to its debilitation and live stranding (Moore et al. 2013). Newly remodeled bony structures along the observed spinal deformation suggest that healing had occurred under different local conditions in mechanical strain (Lagier 1977). Spinal scoliosis has also been observed in another free-swimming right whale with entanglement injuries (Eg 2110 in 2008; Henry et al. 2012) and in a chronically entangled shortfin 
mako shark Isurus oxyrinchus) Wegner \& Cartamil 2012). The development and permanence of these musculoskeletal deformations associated with entanglement drag forces, and their impacts on swimming behaviors and efficiency, are entirely unknown.

\section{Efficiency considerations}

We present the first estimates of ideal and propulsive efficiencies for right whales. Being a relatively rotund cetacean with a large aspect-ratio tail, the right whale has evolved for slow cruising (Woodward et al. 2006). Average propulsive efficiencies for a right whale following disentanglement were (mean \pm SD) $0.25 \pm 0.09$ and $0.26 \pm 0.12$ on descent and ascent, respectively; maximum propulsive efficiencies were 0.50 and 0.51 . These estimates are considerably lower than values for other cetaceans. Fish (1998) estimated maximum propulsive efficiencies of $0.75-$ 0.98 for various toothed whale species, which swim at much higher speeds (6.01-7.91 $\left.\mathrm{m} \mathrm{s}^{-1}\right)$ and therefore face greater selective pressures to develop locomotor efficiency to counter especially high drag. Bose \& Lien (1989) estimated propulsive efficiencies of 0.840.87 for a fin whale, a continuous swimming species that cruises at 4-12 $\mathrm{m} \mathrm{s}^{-1}$. While propulsive efficiency can be expected to be greater than 0.7 at routine swimming speeds, it reaches minima at speeds $<0.5$ $L \mathrm{~s}^{-1}$ (Webb 1975b, Fish 1993, 1998, Fish \& Rohr 1999). The right whale is a much slower swimmer than the odontocetes and cruising balaenopterids that have largely been the focus of marine mammal swimming efficiency studies, with routine speeds of $0.36-1.6 \mathrm{~m} \mathrm{~s}^{-1}$ (Hain et al. 2013), or 0.03-0.16 $\mathrm{L} \mathrm{s}^{-1}$ for Eg 3911's dimensions. Both whales in this study show extremely slow vertical speeds of $0.14-0.68 \mathrm{~m} \mathrm{~s}^{-1}$ in low-drag conditions (0.01-0.07 $\mathrm{L} \mathrm{s}^{-1}$; Table 2). Other slow-moving marine mammals such as manatees and belugas have low propulsive efficiencies of 0.67-0.81 and 0.82-0.84, respectively (Fish 1998, Kojeszewski \& Fish 2007). It is therefore not surprising that a right whale may have lower propulsive efficiency due to its body dimensions, lifestyle and swimming characteristics (Woodward et al. 2006), even in the nonentangled case.

Anderson et al. (1998) showed that the conditions to achieve high efficiency of a flapping foil are: (1) an amplitude of heave motion comparable to chord length, (2) $\theta$ at about $20^{\circ}$ and (3) St between 0.25 and 0.35 . The average chord length for right whales (distance from the caudal peduncle to the fluke notch) is $0.083 \times L$ (Woodward et al. 2006), i.e. $0.83 \mathrm{~m}$ for
Eg 3911-smaller than the estimated fluke stroke amplitudes of $2.0 \mathrm{~m}$ and $1.6 \mathrm{~m}$ in low- and high-drag conditions, respectively. Estimated $\alpha$ generally fell within the $10-15^{\circ}$ range, especially in the low-drag condition (Fig. S2), lower than the $10-30^{\circ}$ observed in highly efficient bottlenose dolphins (Fish 1993). St was mostly $>0.5$. The dimensions and kinematics of right whales therefore approach but do not reach the conditions optimal for propulsion, and additional constraints reduce realized propulsive efficiency.

Overall swimming efficiency, often termed aerobic efficiency, $\eta_{\mathrm{a}}$, is a combination of propulsive (also propeller) efficiency, $\eta_{p}$, and muscular (also metabolic) efficiency, $\eta_{\mathrm{m}}$ (Webb, 1975a). Muscular efficiency is often assumed to be 0.25 for mammals (Kleiber 1961). To consider losses from both propulsion and from muscular energy conversion, $\eta_{a}$ must be multiplicative, i.e. $\eta_{\mathrm{a}}=\eta_{\mathrm{p}} \times \eta_{\mathrm{m}}$. Some previous studies (Goldbogen et al. 2011, Potvin et al. 2012) sum the total losses of 0.75 and 0.10 to obtain $\eta_{\mathrm{a}}=$ 0.15 , instead of multiplying $(0.25 \times 0.90=0.225)$, though 0.15 represents a conservative estimate.

Combining average $\eta_{p}$ for this right whale (Eg 3911) with losses due to muscle activity $\left(\eta_{m}=0.25\right)$ leads to an $\eta_{\mathrm{a}}$ of 0.05 and 0.04 and maximum overall efficiencies of 0.13 and 0.13 for descent and ascent, respectively (Table 4), supporting the conservative 0.15 efficiency factor used in previous studies (Goldbogen et al. 2011, Potvin et al. 2012, van der Hoop et al. 2014b). $\eta_{\mathrm{i}}$ was significantly lower when entangled; although this does not represent the realized case, it illustrates a simpler estimate (based on $C_{\mathrm{T}}$ alone) and that the optimal performance of the system is affected by these different entanglement conditions. However, we did not detect a significant increase in observed $\eta_{\mathrm{p}}$ following disentanglement (Table 4). The observed changes in kinematics may have served to maintain propulsive swimming efficiency across the 2 conditions. It is critical to consider that these efficiency estimates reflect those of a slowmoving, chronically entangled, emaciated and therefore negatively buoyant right whale that was within $18 \mathrm{~d}$ of death.

The most efficient methods of load carrying place the load at the center of mass, as is observed in animals (e.g. crabs and ants, Duysens et al. 2000; aboriginal tribespeople, Heglund et al. 1995). The distribution of these loads can be more important than mass, affecting metabolic rates in humans (Laursen et al. 2000) and kinematics of load-carrying ants (Zollikofer 1994). There is considerable variation in drag forces over the 30-s measurement periods of drag forces on entangling fishing gear in van der Hoop et 
al. (2016). Due to changing flow conditions, whales towing gear will experience variable forces and moments, not necessarily at the center of mass. The mouth is the most common point of attachment of entangling gear for right whales $(77.4 \%)$, and $51.6 \%$ of entanglements involve only the mouth (Johnson et al. 2005). Peduncle entanglements, well behind the center of mass, are less common in northern right whales, though gear often attaches at many points along the body (Johnson et al. 2005). The dynamics of variation in forces and moments at attachment locations other than the center of mass likely have different effects on whale propulsion, efficiency, and gait, though they are unknown at this time.

\section{Conclusions}

Chronic entanglement significantly affects locomotion, the specifics of which depend on the individual. Though the sample size is small, opportunities to tag entangled whales are few and far between, emphasizing the importance of continuing efforts to tag entangled whales with short-duration tags. Even with these limited data, it is apparent that drag significantly affects swimming behaviors and their variability, which contribute to propulsive efficiency.

Acknowledgements. The authors thank field teams involved in the tagging and disentanglement efforts for both animals, Eg 3911 and Eg 4057. Research and tagging were conducted under NOAA Permit 932-1905-00/MA-009526 issued to Dr. Teresa Rowles (Eg 3911) and NMFS Permit 14791 (Eg 4057) issued to D.P.N. We thank reviewers and J.M.v.d.H thesis committee members for comments on the manuscript. J.M.v.d.H was supported by a postgraduate scholarship from the Natural Sciences and Engineering Research Council of Canada, the MIT Martin Family for Sustainability Fellowship, the Herrington Fitch Family Foundation, a NOAA Award \#NA14OAR4320158 to The Cooperative Institute for the North Atlantic Region, and a WHOI-Duke Fellowship through the WHOI Marine Mammal Center.

\section{LITERATURE CITED}

Adachi T, Maresh JL, Robinson PW, Peterson SH, and others (2014) The foraging benefits of being fat in a highly migratory marine mammal. Proc R Soc B 281:20142120

Anderson JM, Streitlien K, Barrett DS, Triantafyllou MS (1998) Oscillating foils of high propulsive efficiency. J Fluid Mech 360:41-72

Aoki K, Watanabe YY, Crocker DE, Robinson PW and others (2011) Northern elephant seals adjust gliding and stroking patterns with changes in buoyancy: validation of at-sea metrics of body density. J Exp Biol 214:2973-2987

Bertram JE (2005) Constrained optimization in human walking: cost minimization and gait plasticity. J Exp Biol 208: 979-991
Bertram JE (2015) Locomotion: why we walk the way we walk. Curr Biol 25:R795-R797

*Buw M, McConnell B, Bradshaw CJA, Burton H, Fedak MA (2003) Blubber and buoyancy: monitoring the body condition of free-ranging seals using simple dive characteristics. J Exp Biol 206:3405-3423

Blake RW (1983) Fish locomotion. Cambridge University Press, Cambridge

Bonnard M, Pailhous J (1991) Intentional compensation for selective loading affecting human gait phases. J Mot Behav 23:4-12

* Bose N, Lien J (1989) Propulsion of a fin whale (Balaenoptera physalus): Why the fin whale is a fast swimmer. Proc $\mathrm{R}$ Soc B 237:175-200

* Boyd IL, McCafferty DJ, Walker TR (1997) Variation in foraging effort by lactating Antarctic fur seals: response to simulated increased foraging costs. Behav Ecol Sociobiol 40:135-144

Chopra MG, Kambe T (1977) Hydromechanics of lunate-tail swimming propulsion. Part 2. J Fluid Mech 79:49-69

Cornick LA, Inglis SD, Willis K, Horning M (2006) Effects of increased swimming costs on foraging behavior and efficiency of captive Steller sea lions: evidence for behavioral plasticity in the recovery phase of dives. J Exp Mar Biol Ecol 333:306-314

Daniel T (1991) Efficiency in aquatic locomotion: limitations from single cells to animals. In: Blake RW (ed) Efficiency and economy in animal physiology. Cambridge University Press, Cambridge, p 83-95

* Duysens J, Clarac F, Cruse H (2000) Load-regulating mechanisms in gait and posture: comparative aspects. Physiol Rev 80:84-133

* Ebbeling CJ, Hamill J, Crussemeyer JA (1994) Lower extremity mechanics and energy cost of walking in highheeled shoes. J Orthop Sports Phys Ther 19:190-196

Eloy C (2012) Optimal Strouhal number for swimming animals. J Fluids Structures 30:205-218

Fish FE (1993) Power output and propulsive efficiency of swimming bottlenose dolphins (Tursiops truncatus). J Exp Biol 185:179-193

Fish FE (1998) Comparative kinematics and hydrodynamics of odontocete cetaceans: morphological and ecological correlates with swimming performance. J Exp Biol 201: 2867-2877

Fish FE (1999) Performance constraints on the maneuverability of flexible and rigid biological systems. In: Eleventh international symposium on unmanned untethered submersible technology, Durham, NH. Autonomous Undersea Systems Institute, Durham, NH, p 394-406

Fish FE, Lauder GV (2006) Passive and active flow control by swimming fishes and mammals. Annu Rev Fluid Mech 38:193-224

Fish FE, Rohr JJ (1999) Review of dolphin hydrodynamics and swimming performance. Tech Rep 1801 US Navy SPAWAR Systems Center, San Diego, CA

Fish FE, Peacock JE, Rorh JJ (2003) Stabilization mechanism in swimming odontocete cetaceans by phased movements. Mar Mamm Sci 19:515-528

Fish FE, Legac P, Williams TM, Wei T (2014) Measurement of hydrodynamic force generation by swimming dolphins using bubble DPIV. J Exp Biol 217:252-260

Gailey R, Allen K, Castles J, Kucharik J, Roeder M (2008) Review of secondary physical conditions associated with lower-limb amputation and long-term prosthesis use. J Rehabil Res Dev 45:15-29 
Goldbogen JA, Calambokidis J, Oleson E, Potvin J, Pyenson ND, Schorr G, Shadwick RE (2011) Mechanics, hydrodynamics and energetics of blue whale lunge feeding: efficiency dependence on krill density. J Exp Biol 214: 131-146

Hain JHW, Hampp JD, McKenney SA, Albert JA, Kenney RD (2013) Swim speed, behavior, and movement of North Atlantic right whales (Eubalaena glacialis) in coastal waters of northeastern Florida, USA. PLOS ONE 8:e54340

Heglund NC, Willems PA, Penta M, Cavagna GA (1995) Energy-saving gait mechanics with head-supported loads. Nature 375:52-54

Henry AG, Cole TVN, Garron M, Ledwell W, Reid A (2012) Mortality and serious injury determinations for baleen whale stocks along the Gulf of Mexico, United States east coast and Atlantic Canadian provinces, 2006-2010. US Department of Commerce, Northeast Fisheries Science Center Reference Document 12-11. http://nefsc. noaa.gov/publications/

Hertel H (1969) Hydrodynamics of swimming and wave-riding dolphins. In: Anderson HT (ed) The biology of marine mammals. Academic Press, New York, NY, p 31-63

Hover FS, Haugsdal Ø, Triantafyllou MS (2004) Effect of angle of attack profiles in flapping foil propulsion. J Fluids Structures 19:37-47

Johnson M (2015). DTAG Toolbox for MATLAB. http:// soundtags.st-andrews.ac.uk/dtags/dtag-toolbox/

Johnson M, Tyack P (2003) A digital acoustic recording tag for measuring the response of wild marine mammals to sound. IEEE J Oceanic Eng 28:3-12

Johnson A, Salvador G, Kenney J, Robbins J, Kraus S, Landry S, Clapham P (2005) Fishing gear involved in entanglements of right and humpback whales. Mar Mamm Sci 21:635-645

Kleiber M (1961) The fire of life: an introduction to animal energetics. Wiley, New York, NY

Knowlton AR, Hamilton PK, Marx MK, Pettis HM, Kraus SD (2012) Monitoring North Atlantic right whale Eubalaena glacialis entanglement rates: a $30 \mathrm{yr}$ retrospective. Mar Ecol Prog Ser 466:293-302

Kojeszewski T, Fish FE (2007) Swimming kinematics of the Florida manatee (Trichechus manatus latirostris): hydrodynamic analysis of an undulatory mammalian swimmer. J Exp Biol 210:2411-2418

Kooyman GL, Ponganis PJ (1994) Emperor penguin oxygen consumption, heart rate and plasma lactate levels during graded swimming exercise. J Exp Biol 195:199-209

Lagier R (1977) Spondylosis in the whale - an anatomicoradiological study of an osteophyte. Scand J Rheumatol 6: 245-249

Lang TG, Daybell DA (1963) Porpoise performance tests in a sea-water tank. NOTS Technical Paper 3063, NAVWEPS Report 8060, US Naval Ordnance Test Station, China Lake, CA

Laursen B, Ekner D, Simonsen EB, Voigt M, Sjøgaard G (2000) Kinetics and energetics during uphill and downhill carrying of different weights. Appl Ergon 31: 159-166

* Lovvorn JR, Watanuki Y, Kato A, Naito Y, Liggins GA (2004) Stroke patterns and regulation of swim speed and energy cost in free-ranging Brunnich's guillemots. J Exp Biol 207:4679-4695

Maresh JL, Simmons SE, Crocker DE, McDonald BI, Williams TM, Costa DP (2014) Free-swimming northern elephant seals have low field metabolic rates that are sensitive to an increased cost of transport. J Exp Biol 217: 1485-1495

MATLAB (2014) MATLAB and Statistics Toolbox Release 2014b. www.mathworks.com

McCarron P, Tetreault H (2012) Lobster pot gear configurations in the Gulf of Maine. Maine Lobstermen's Association, Kennebunk, ME. www.bycatch.org/sites/default/ files/Lobster_Gear_Report_0.pdf

McGregor AEN (2010) The cost of locomotion in North Atlantic right whales Eubalaena glacialis. $\mathrm{PhD}$ thesis, Department of Marine Science and Conservation, Duke University, Durham, NC

Methling C, Tudorache C, Skov PV, Steffensen JF (2011) Pop up satellite tags impair swimming performance and energetics of the European eel (Anguilla anguilla). PLOS ONE 6:e20797

Miller PJO, Johnson M, Tyack P, Terray EA (2004) Swimming gaits, passive drag and buoyancy of diving sperm whales Physeter macrocephalus. J Exp Biol 207: 1953-1967

* Miller PJ, Biuw M, Watanabe YY, Thompson D, Fedak MA (2012) Sink fast and swim harder! Round-trip cost-oftransport for buoyant divers. J Exp Biol 215:3622-3630

Moore MJ, Knowlton AR, Kraus SD, McLellan WA, Bonde RK (2004) Morphometry, gross morphology and available histopathology in North Atlantic right whale (Eubalaena glacialis) mortalities (1970-2002). J Cetacean Res Manag 6:199-214

* Moore M, Walsh M, Bailey J, Brunson D, and others (2010) Sedation at sea of entangled North Atlantic right whales (Eubalaena glacialis) to enhance disentanglement. PLOS ONE 5:e9597

* Moore MJ, van der Hoop JM, Barco SG, Costidis AM and others (2013) Criteria and case definitions for serious injury and death of pinnipeds and cetaceans caused by anthropogenic trauma. Dis Aquat Org 103:229-264

Muijres FT, Spedding GR, Winter Y, Hedenström A (2011) Actuator disk model and span efficiency of flapping flight in bats based on time-resolved PIV measurements. Exp Fluids 51:511-525

NARWC (North Atlantic Right Whale Consortium) (2015) North Atlantic Right Whale Consortium Database, 18 Feb 2015. New England Aquarium, Boston, MA

NMFS (National Marine Fisheries Service) (2003) Report of the workshop on large whale disentanglement: learning from the past and moving towards the future (ed: Clapham PJ). National Marine Fisheries Service Northeast Regional Office, Boston, MA. https://www.greateratlantic.fisheries. noaa.gov/whaletrp/plan/disent/Disentanglement\%20W.S. ReportFinal3.pdf

Noren SR, Redfern JV, Edwards EF (2011) Pregnancy is a drag: hydrodynamics, kinematics and performance in pre- and post-parturition bottlenose dolphins (Tursiops truncatus). J Exp Biol 214:4151-4159

Nousek-McGregor AE, Miller CA, Moore MJ, Nowacek DP (2014) Effects of body condition on buoyancy in endangered North Atlantic right whales. Physiol Biochem Zool 87:160-171

Nowacek DP, Johnson MP, Tyack PL, Shorter KA, McLellan WA, Pabst DA (2001) Buoyant balaenids: the ups and downs of buoyancy in right whales. Proc R Soc B 268: 1811-1816

Nudds RL, John EL, Keen AN, Shiels HA (2014) Rainbow trout provide the first experimental evidence for adher- 
ence to a distinct Strouhal number during animal oscillatory propulsion. J Exp Biol 217:2244-2249

Opila-Correia KA (1990) Kinematics of high-heeled gait with consideration for age and experience of wearers. Arch Phys Med Rehabil 71:905-909

Pircio AW, Gylys JA, Cavanagh RL, Buyniski JP, Bierwagen ME (1976) Pharmacology of butorphanol, a 3,14-dihydroxymorphinan narcotic-antagonist analgesic. Arch Int Pharmacodyn Ther 220:231-257

Ponganis PJ, Kooyman GL, Zornow MH, Castellini MA, Croll DA (1990) Cardiac output and stroke volume in swimming harbor seals. J Comp Physiol B 160:473-482

Potvin J, Goldbogen JA, Shadwick RE (2012) Metabolic expenditures of lunge feeding rorquals across scale: implications for the evolution of filter feeding and the limits to maximum body size. PLOS ONE 7:e44854

Prandtl L (1952) Essentials of fluid dynamics: with applications to hydraulics aeronautics, meteorology, and other subjects. Hafner Publishing Company, New York, NY

R Core Team (2015) R: a language and environment for statistical computing. R Foundation for Statistical Computing, Vienna

Rayner JMV (1979) A vortex theory of animal flight. Part 1. The vortex wake of a hovering animal. J Fluid Mech 91: $697-730$

Reves JG, Fragen RJ, Vinik HR, Greenblatt DJ (1985) Midazolam-pharmacology and uses. Anesthesiology 62: 310-324

Sarwahi V, Boachie-Adjei O, Backus SI, Taira G (2002) Characterization of gait function in patients with postsurgical sagittal (flatback) deformity: a prospective study of 21 patients. Spine 27:2328-2337

Selinger JC, O'Connor SM, Wong JD, Donelan JM (2015) Humans can continuously optimize energetic cost during walking. Curr Biol 25:2452-2456

Shimojo H, Sengoku Y, Miyoshi T, Tsubakimoto S, Takagi H (2014) Effect of imposing changes in kick frequency on kinematics during undulatory underwater swimming at maximal effort in male swimmers. Hum Mov Sci 38: 94-105

Simon M, Johnson M, Tyack P, Madsen PT (2009) Behaviour and kinematics of continuous ram filtration in bowhead whales (Balaena mysticetus). Proc R Soc B 276:3819-3828

Simon M, Johnson M, Madsen PT (2012) Keeping momentum with a mouthful of water: behavior and kinematics of humpback whale lunge feeding. J Exp Biol 215:3786-3798

Skrovan RC, Williams TM, Berry PS, Moore PW, Davis RW (1999) The diving physiology of bottlenose dolphins (Tur- siops truncatus). II. Biomechanics and changes in buoyancy at depth. J Exp Biol 202:2749-2761

* Triantafyllou GS, Triantafyllou MS, Grosenbaugh MA (1993) Optimal thrust development in oscillating foils with application to fish propulsion. J Fluids Structures 7 : 205-224

*van der Hoop JM, Moore MJ, Barco SG, Cole TV and others (2013) Assessment of management to mitigate anthropogenic effects on large whales. Conserv Biol 27: 121-133

*van der Hoop JM, Fahlman A, Hurst T, Rocho-Levine J, Shorter KA, Petrov V, Moore MJ (2014a) Bottlenose dolphins modify behavior to reduce metabolic effect of tag attachment. J Exp Biol 217:4229-4236

* van der Hoop JM, Moore MJ, Fahlman A, Bocconcelli A and others (2014b) Behavioral impacts of disentanglement of a right whale under sedation and the energetic cost of entanglement. Mar Mamm Sci 30:282-307

van der Hoop JM, Corkeron P, Kenney J, Landry S, Morin D, Smith J, Moore MJ (2016) Drag from fishing gear entangling North Atlantic right whales. Mar Mamm Sci 32: 619-642

Webb PM (1975a) Efficiency of pectoral-fin propulsion of Cymatogaster aggregata. In: Wu TY, Brokaw CJ, Brennen $C$ (eds) Swimming and flying in nature, vol 2 Plenum Press, New York, NY, p 573-584

Webb PW (1975b) Hydrodynamics and energetics of fish propulsion. Bull Fish Res Board Can 190:1-158

Wegner NC, Cartamil DP (2012) Effects of prolonged entanglement in discarded fishing gear with substantive biofouling on the health and behavior of an adult shortfin mako shark, Isurus oxyrinchus. Mar Pollut Bull 64: 391-394

Williams TM (1999) The evolution of cost efficient swimming in marine mammals: limits to energetic optimization. Philos Trans R Soc Lond B Biol Sci 354:193-201

Woodward BL (2006) Locomotory strategies, dive dynamics, and functional morphology of the mysticetes: using morphometrics, osteology, and Dtag data to compare swim performance in four species of baleen whales. $\mathrm{PhD}$ thesis, Mechanical Engineering and Marine Sciences, University of Maine, Orono, ME

*Woodward BL, Winn JP, Fish FE (2006) Morphological specializations of baleen whales associated with hydrodynamic performance and ecological niche. J Morphol 267:1284-1294

Zollikofer CPE (1994) Stepping patterns in ants. III. Influence of load. J Exp Biol 192:119-127

Submitted: April 4, 2016; Accepted: October 22, 2016

Proofs received from author(s): December 15, 2016
Editorial responsibility: Robert Harcourt,

Sydney, New South Wales, Australia 